\title{
Pathfinding and Target Selection by Developing Geniculocortical Axons
}

\author{
Anirvan Ghosh and Carla J. Shatz \\ Department of Neurobiology, Stanford University School of Medicine, Stanford, California 94305
}

During development of the mammalian cerebral cortex, thalamic axons must grow into the telencephalon and select appropriate cortical targets. In order to begin to understand the cellular interactions that are important in cortical target selection by thalamic axons, we have examined the morphology of axons from the lateral geniculate nucleus (LGN) as they navigate their way to the primary visual cortex. The morphology of geniculocortical axons was revealed by placing the lipophilic tracer Dil into the LGN of paraformaldehydefixed brains from fetal and neonatal cats between embryonic day 26 (E26; gestation is $65 \mathrm{~d}$ ) and postnatal day 7 (P7).

This morphological approach has led to three major observations. (1) As LGN axons grow within the intermediate zone of the telencephalon toward future visual cortex (E3040), many give off distinct interstitial axon collaterals that penetrate the subplate of nonvisual cortical areas. These collaterals are transient and are not seen postnatally. (2) There is a prolonged period during which LGN axons are restricted to the visual subplate prior to their ingrowth into the cortical plate; the first LGN axons arrive within visual subplate by E36 but are not detected in layer 6 of visual cortex until about E50. (3) Within the visual subplate, LGN axons extend widespread terminal branches. This represents a marked change in their morphology from the simple growth cones present earlier as LGN axons navigate en route to visual cortex.

The presence of interstitial collaterals suggests that there may be ongoing interactions between LGN axons and subplate neurons along the entire intracortical route traversed by the axons. From the extensive branching of LGN axons within the visual subplate during the waiting period, it appears that they are not simply "waiting." Rather, LGN axons may participate in dynamic cellular interactions within the subplate long before they contact their ultimate target neurons in layer 4. These observations confirm the existence of a prolonged waiting period in the development of thalamocortical connections and provide important morphological evidence in support of the previous suggestion that interactions between thalamic axons and subplate neurons are necessary for cortical target selection.

\footnotetext{
Received May 31, 1991; revised July 29, 1991; accepted July 30, 1991.

We thank Drs. E. I. Knudsen, J. H. P. Skene, and W. T. Newsome for useful comments on the manuscript, and $R$. Yamawaki for help with fetal surgeries. This work was supported by NIH Grant EY02858 to C.J.S. and NIH Training Grant HD07249 to A.G.

Correspondence should be addressed to Dr. Carla J. Shatz, Division of Neurobiology, Department of Molecular and Cell Biology, LSA 221, University of California, Berkeley, CA 94720.

Copyright $(\mathbb{C} 1992$ Society for Neuroscience $0270-6474 / 92 / 120039-17 \$ 05.00 / 0$
}

In the mammalian brain, most of the sensory information from the periphery is relayed to the cerebral cortex via the thalamus. Neurons in distinct nuclei of the thalamus project to different areas of the cortex. For example, in the visual pathway neurons of the lateral geniculate nucleus (LGN) project to the dorsal and posterior regions of the cerebral hemispheres, whereas neurons of the medial geniculate nucleus (MGN) project to lateral cortex as part of the primary auditory pathway. In order to understand how appropriate connections form between neurons of the thalamus and their cortical targets, we have studied the morphological development of axons of LGN neurons in fetal and neonatal cats from the time of initial outgrowth to the time when LGN axons arrive at their ultimate target, cortical layer 4.

In the adult cat visual system, LGN axons project primarily to layer 4 of cortical areas 17 and 18 (Garey and Powell, 1967; Wilson and Cragg, 1967; Niimi and Sprague, 1970; Rosenquist et al., 1974). The LGN axon terminals representing each eye are segregated from each other in layer 4 , giving rise to the periodic system of ocular dominance columns (Hubel and Wiesel, 1962, 1969, 1972; Shatz et al., 1977; Anderson et al., 1988). Previous studies using the transneuronal transport of radioactive amino acids have defined the time course of development of the geniculocortical projection (LeVay et al., 1978; Shatz and Luskin, 1986). In the cat, radioactive label representing LGN axons can be detected in the vicinity of future visual cortex as early as embryonic day 40 (E40; gestation is 65 d) (Shat7 and Luskin, 1986). However, label cannot be detected within the cortical plate until E55. Between E40 and E55, radioactive label is restricted to the zone below the cortical plate, called the subplate. Thus, LGN axons seem to wait in the subplate below visual cortex for an extended period of time before growing into the cortical plate. This period has been called the "waiting period" and has been found to be a common feature of many axonal systems growing into the cortex (Rakic, 1977; Wise et al., 1977; Wise and Jones, 1978; Innocenti, 1981). Autoradiographic evidence also indicates that, in the cat, by postnatal day 7 (P7) LGN axons have grown into the cortex and are largely restricted to layer 4 (LeVay et al., 1978; Shatz and Luskin, 1986). At this age geniculocortical axons representing the two eyes are intermixed with each other. The axons begin segregating at about 3 weeks after birth, and eye-specific axon segregation is largely complete by about the sixth postnatal week, giving rise to the periodic system of ocular dominance columns (LeVay et al., 1978).

In the present study we have used the lipophilic tracer DiI (1,1'-dioctadecyl-3,3,3',3'-tetramethylindocarbocyanine percholate; Godement et al., 1987) to label LGN axons in aldehydefixed brains. In contrast to autoradiographic tracing, this tech- 


\begin{tabular}{ll}
\hline Table 1. Age distribution of reconstructed LGN axons \\
Age at perfusion & $\begin{array}{l}\text { Number of axons } \\
\text { reconstructed }\end{array}$ \\
\hline E26-E35 & 15 \\
E36-E45 & 14 \\
E46-E55 & 20 \\
E56-E65 (=P0) & 9 \\
P1-P7 & 11 \\
Total axons reconstructed & 69 \\
\hline
\end{tabular}

nique allows the visualization of single axons and growth cones in fetal and neonatal brains. In particular, we have studied in detail the morphology of LGN axons during the waiting period in the development of the cat's geniculocortical projection. During this period, LGN axons accumulate in the subplate, a zone that contains a special population of neurons, the subplate neurons. These neurons acquire many characteristics of mature neurons during fetal development, and then almost all of them die early in postnatal life (Chun and Shatz, 1989a,b; Kostovic and Rakic, 1990; for review, see Shatz et al., 1990). Subplate neurons are the first postmitotic neurons of the telencephalon (Kostovic and Rakic, 1980; Luskin and Shatz, 1985a,b). They are known to receive synapses on their somata and dendrites (Chun and Shatz, 1988), and many of them can be synaptically driven by white matter stimulation in cortical slices (Friauf et al., 1990). These neurons send the first cortical efferent projections to the thalamus and other subcortical targets and maintain a projection to the LGN during fetal life (McConnell et al., 1989). Moreover, ablating visual subplate neurons at the beginning of the waiting period prevents LGN axons from recognizing and innervating visual cortex (Ghosh et al., 1990). Therefore, we were especially interested in examining the morphology of LGN axons within the subplate to learn more about the interaction of these axons with subplate neurons. In addition, in view of the recent report that there is no waiting period in thalamocortical development in rodents (Catalano et al., 1991), we wished to reexamine this issue in the cat using the more sensitive technique of DiI labeling.

\section{Materials and Methods}

Geniculocortical axons were labeled by placing crystals of DiI into the LGN of paraformaldehyde-fixed brains. Sixty-nine LGN axons from animals aged E26 (gestation is 65 d) to P7 were reconstructed using camera lucida and analyzed; the age distribution of axons examined is shown in Table 1.

Surgical procedure. All procedures included sterile surgical technique to externalize fetuses by cesarian section. Timed-pregnant cats were initially anesthetized by intramuscular injection of ketamine hydrochloride $(20 \mathrm{mg} / \mathrm{kg})$ and acepromazine $(0.2 \mathrm{mg} / \mathrm{kg})$. Anesthesia was maintained by halothane $\left(0.5-2 \%\right.$ in $\left.\mathrm{O}_{2}\right)$ administered through an endotrachial tube, and the appropriate level was monitored by ventilation, heart rate, and withdrawal reflexes. A $5 \%$ dextrose/saline intravenous drip was maintained throughout the surgery. Terbutaline sulfate was administered $(0.03 \mathrm{mg} / \mathrm{kg}$, i.v.) before each fetal manipulation to prevent uterine contraction. After surgery, the animals were given analgesics and monitored in the $24 \mathrm{hr} / \mathrm{d}$ intensive care unit for at least $36 \mathrm{hr}$. Further details of the surgical procedure can be found in Luskin and Shatz (1985a).

Tissue preparation for histology. Fetal animals were anesthetized transplacentally through maternal anesthesia; postnatal animals were deeply anesthetized by an intraperitoneal injection of Nembutal $(35 \mathrm{mg} /$ $\mathrm{kg}$ ). Animals were perfused transcardially using a peristaltic pump with $0.1 \mathrm{M}$ sodium phosphate buffer ( $\mathrm{pH} 7.4$ ), followed by $4 \%$ paraformal- dehyde in the same buffer. Following perfusion, the cranium was removed and the brain was placed in the same fixative.

DiI injections. To visualize geniculocortical axons, small crystals of DiI (Molecular Probes, D282) were placed into the LGN of fixed brains using insect pins. Throughout most of development, with the exception of the earliest ages studied (E26-36), the LGN appears as a distinct bulge on the dorsolateral surface of the thalamus, permitting the accurate visual placement of Dil crystals. The location of the LGN between E26 and E36 was estimated based on the region of the thalamus where the earliest retinal axons have been shown to terminate using intraocular injections of radioactive amino acids (Shatz, 1983). At E36 the location of the LGN was also verified by retrogradely labeling thalamic neurons from posterior neocortex (presumptive visual cortex). In animals older than P5, DiI was placed into the optic radiations in 1 -mm-thick coronal slices through visual cortex because DiI labeling from the LGN did not work at these ages; LGN axons in these experiments were identified based on their adultlike arborization patterns within layers 1, 4, and 6 of visual cortex (Gilbert and Wiesel, 1979; Humphrey et al., 1985a,b). The DiI-injected brains were stored in $4 \%$ paraformaldehyde in $0.1 \mathrm{M}$ sodium phosphate buffer (with $0.05 \%$ sodium azide) at room temperature, or at $37^{\circ} \mathrm{C}$, for $2-5$ months to allow for diffusion of the label. Coronal sections (100-200 $\mu \mathrm{m})$ were cut on a vibratome, coverslipped with glycerol, and viewed under rhodamine epifluorescence optics. The various zones of the cerebral wall (marginal zone, cortical plate, intermediate zone, and ventricular zone) were identified by counterstaining sections with the fluorescent counterstain meta-phenylenediamine (MPD; Quinn and Weber, 1988), which appears green under fluorescence optics.

Reconstruction of individual axons. Individual DiI-labeled axons from $200-\mu \mathrm{m}$-thick vibratome sections were drawn using a camera lucida with a $40 \times$ water-immersion objective and a $10 \times$ eyepiece. The high density of DiI-labeled axons usually made it impossible to follow single axons over several sections. Consequently, only axons with most, if not all, terminal branches (identified by the presence of growth cones) restricted to a single section were drawn and analyzed. Since Dil is transported both anterogradely and retrogradely, it was important not to mistake the axon collaterals of retrogradely labeled subplate or cortical plate neurons for geniculocortical axons. This was achieved by limiting axon reconstructions to cases where each axon could be traced back to the optic radiations and by selecting sections that had very few, if any, retrogradely labeled cells. In several instances DiI-labeled sections were photoconverted to obtain an electron-dense diaminobenzidine (DAB; Sigma Chemical Co.) reaction product for photographic purposes.

Photoconversion. Dil-labeled sections were incubated in a cold, filtered solution of DAB (75 mg of DAB in $50 \mathrm{ml}$ of Tris buffer, $\mathrm{pH} \mathrm{8.2)}$ for $2 \mathrm{hr}$ before being illuminated in the same solution under rhodamine epifluorescence optics. A dense DAB reaction product in DiI-labeled axons was clearly visible in $30-60 \mathrm{~min}$. Sections were subsequently washed in Tris buffer ( $\mathrm{pH} 7.4$ ), dehydrated, and coverslipped with Permount. This procedure is similar to ones described previously (Maranto, 1982; Sandell and Masland, 1988).

\section{Results}

We have examined the morphological changes in LGN axons from E30 to P7 in the cat. E30 was selected as the starting point for our study because it is the earliest age at which an injection of DiI into the LGN labels axons within the telencephalon proper, rather than within the thalamus or internal capsule. LGN neurons are generated between E21 and E31, and the nucleus itself cannot be readily identified until about E30, when many of the earliest-born neurons have completed their migration from the ventricular zone (Shatz, 1983; Hickey and Hitchcock, 1984). P7 was chosen as the end point of our study because at this age the majority of LGN axons have arrived within cortical layer 4 , where they will eventually segregate into ocular dominance columns. Thus, the period between E30 and P7 is one in which LGN axons must grow along the correct pathway through the developing cortical white matter, select visual cortex as the appropriate cortical target, and invade and arborize within layer 4.

The appearance of the LGN as a distinct bulge in the dor- 
A

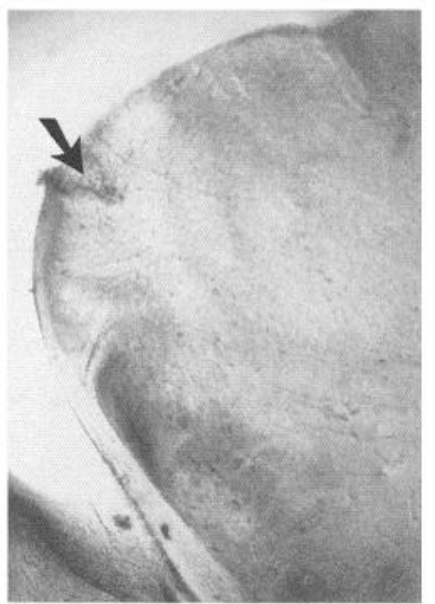

B

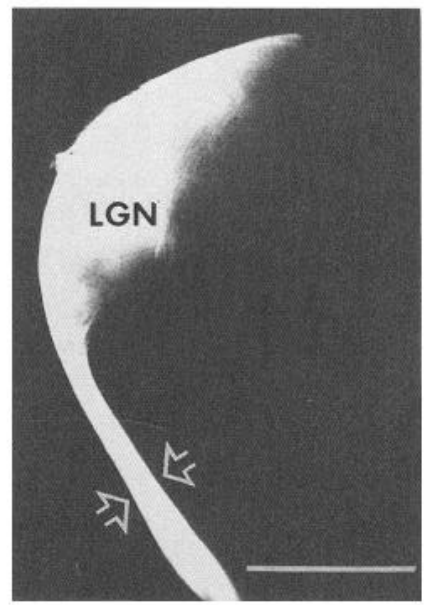

Figure 1. DiI placement site in the LGN at E43. A, The Dil injection site, marked by an arrow, can be seen under bright-field illumination in this $200 \mu \mathrm{m}$ coronal section near the dorsolateral surface of the thalamus. $B$, The diffusion of DiI near the injection site after the brain had been stored in fixative for 2 months is shown in the same section as in $A$ under rhodamine epifluorescence. The DiI label has diffused throughout the LGN but not into other thalamic nuclei. The optic tract, which contains retinal ganglion cell axons projecting to the LGN, is also heavily labeled retrogradely (open arrows). Scale bar, $1 \mathrm{~mm}$.

solateral surface of the thalamus allowed us to position the DiI crystals accurately at most ages. An example of a DiI injection site in the LGN at E43 is shown in Figure 1, $A$ and $B$. When a few crystals of DiI are inserted into the LGN, labeling is restricted almost exclusively to the nucleus. Since DiI diffuses passively along membranes, it can travel both anterogradely and retrogradely. Thus, as shown in Figure $1 B$, the optic tract containing retrogradely labeled axons of retinal ganglion cells is also labeled selectively, confirming accurate and restricted placement of the tracer within the LGN.

\section{Survey of geniculocortical axon development}

The general features of development of the geniculocortical projection are shown in Figures 2 and 3. At E30 the first axons from dorsolateral thalamus have entered the telencephalon (Fig. $2 A)$. Once in the telencephalon, LGN axons travel within the intermediate zone (between the cortical plate and the ventricular zone) dorsally and posteriorly toward the region of future visual cortex. By E36, growth cones of the very first LGN axons can be detected within a fascicle of fibers below visual cortex (Fig. $2 B, C$ ); this fascicle is called the optic radiations. Between E36 and E50 there is a striking increase in the number of axons that are present in the vicinity of visual cortex. However, instead of growing into the cortical plate upon arrival, these axons accumulate within the subplate zone below visual cortex (a region we shall refer to as visual subplate) to form a dense plexus of fibers, as shown in Figure $3 A$ at E50. At E50 the first LGN axons can also be seen within the cortical plate, and by E60 many of them have traversed past layers 6 and 5 , and entered layer 4 (Fig. $3 B$ ). Once within layer 4 , axons begin to branch so that by P7 distinct terminal arbors can be recognized (e.g., see Fig. 15). DiI placement into the optic radiations at P20 reveals a large number of highly branched LGN axons present in layers 4 and 6 of visual cortex (Fig. 3C).

This basic description of the development of the geniculocortical projection confirms and extends previous observations based on autoradiographic labeling techniques. The compara-
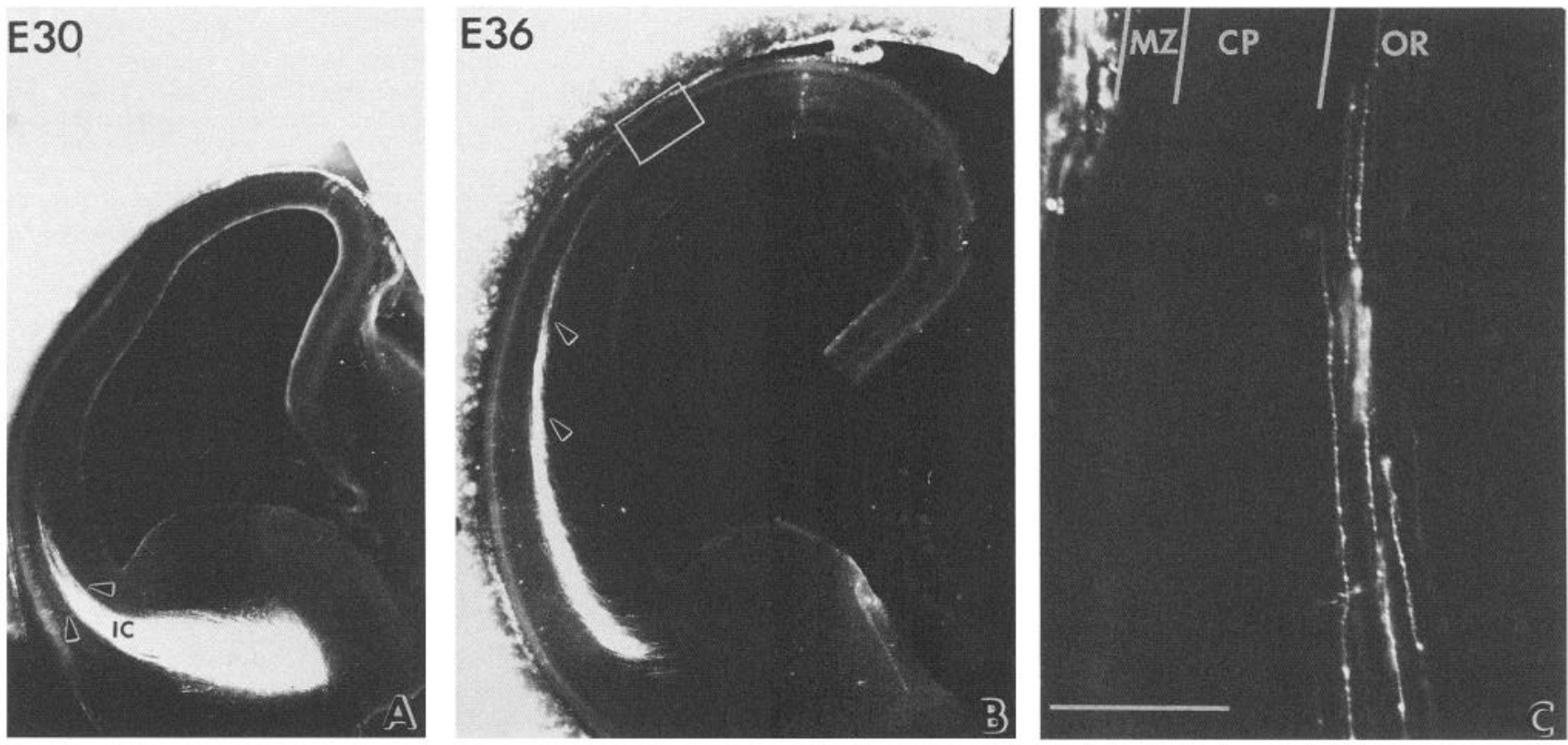

Figure 2. The location of thalamocortical axons within the telencephalon at E30 and E36 as seen in coronal sections. A, At E30, DiI-labeled axons (arrowheads) can be seen within the internal capsule $(I C)$ and the intermediate zone of the lateral telencephalon following placement of DiI into dorsolateral thalamus (presumptive LGN) on the ipsilateral side. B. At E36, DiI placement into the LGN results in the labeling of a tight fascicle of axons, the optic radiations, within the intermediate zone of the lateral telencephalon (arrowheads) and a few axons near dorsal telencephalon (region of future visual cortex). $C$, Individual DiI labeled axons within the optic radiations $(O R)$ can be seen approaching presumptive visual cortex in this higher-magnification view of the boxed region in $B$. Dorsal is $u p$; lateral is to the left. $M Z$, marginal zone; $C P$, cortical plate. Scale bar: 1 $\mathrm{mm}$ for $A$ and $B ; 150 \mu \mathrm{m}$ for $C$. 
E50

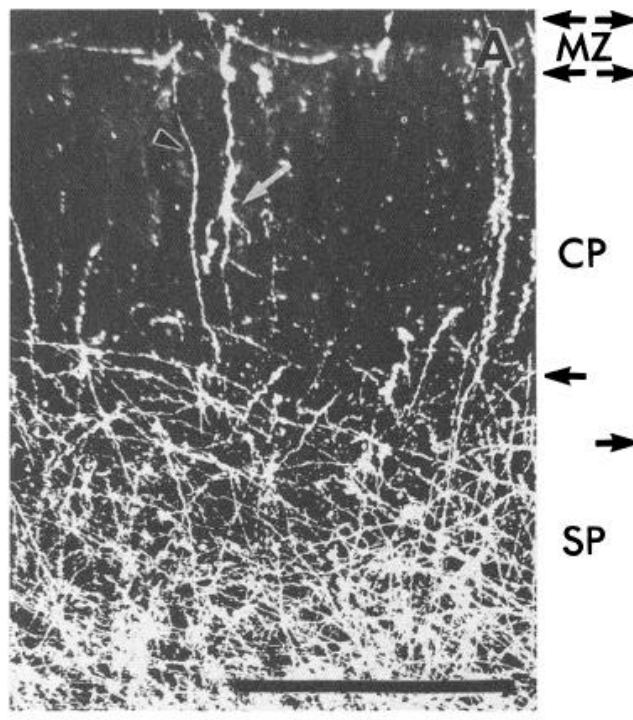

E60

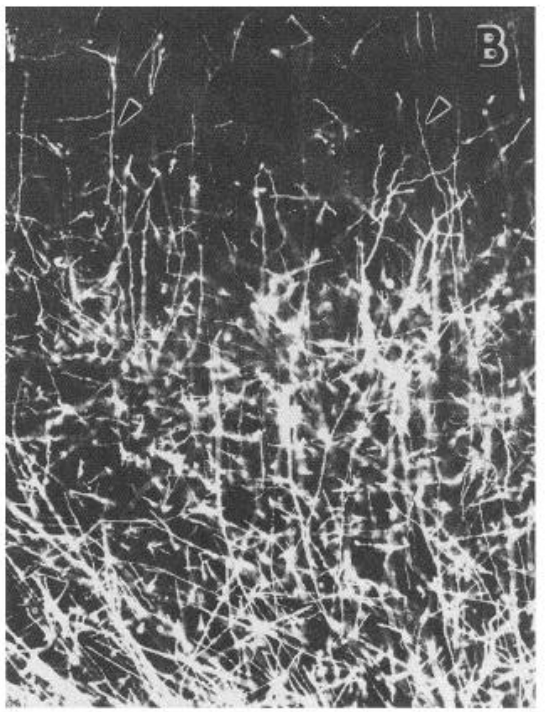

P20

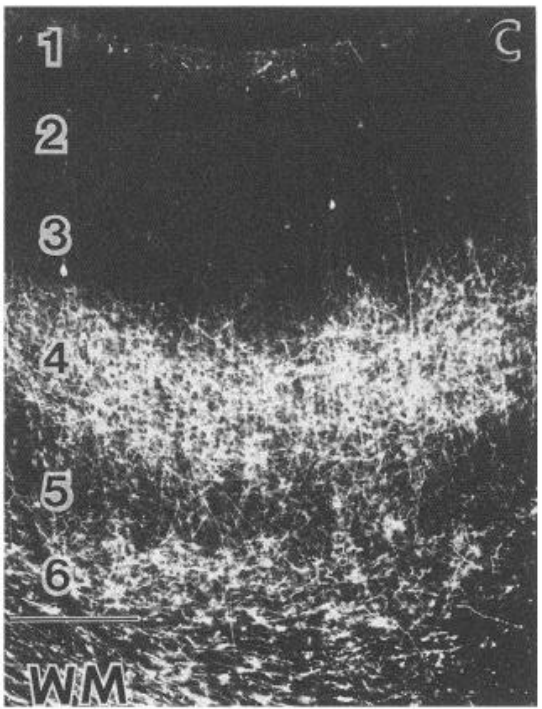

Figure 3. The location of LGN axons in the visual cortex at E50, E60, and P20. A, At E50, a large number of axons labeled from the LGN can be seen restricted to the visual subplate $(S P)$ immediately below the cortical plate $(C P)$. The occasional cellular elements labeled within the cortical plate are axons that grow into the marginal zone $(M Z$; arrowhead) and retrogradely labeled cortical pyramidal neurons that have axons at or near the thalamic injection site (arrow). B, At E60, many DiI-labeled LGN axons (arrowheads) can be seen within the cortical plate, while a large number are still present in the subplate. $C$, At P20, axons labeled in the visual cortex from a DiI placement in the optic radiations are largely restricted to layers 4 and $6 . W M$, white matter. Scale bar, $500 \mu \mathrm{m}$ for $A-C$.

tively better resolution of DiI labeling reveals that LGN axons arrive near visual cortex by E36 (see also Fig. 7) but are not present in the cortical plate until E50. Previously, in the cat, the waiting period below visual cortex was believed to extend from E40 until E55 based on transneuronal autoradiographic labeling experiments (Shatz and Luskin, 1986). The present observations confirm the existence of a prolonged period when LGN axons remain confined to visual subplate, but indicate also that LGN axon growth is further advanced than previously thought with respect to the neurogenesis of target cortical neurons. Whereas the first LGN axons are present below visual cortex by E36, their primary target layer 4 neurons are not generated in the ventricular zone until E38 (Shatz and Luskin, 1986). Our experiments also indicate that LGN axons undergo several stages of morphological development before arriving in cortical layer 4 . These morphological changes are detailed below.

\section{Growth cone morphology of developing geniculocortical axons}

Growth cones are considered to be important in axon elongation and pathfinding, and it has been suggested that growth cone morphology may be related to the complexity of pathfinding decisions being made by the axon (Goodman et al., 1984; Tosney and Landmesser, 1985a; Bentley and Toroian-Raymond, 1986; Bovolenta and Mason, 1987). Since LGN axons at different developmental stages and at different points along the geniculocortical pathway may be faced with different local environments, it was of interest to examine the growth cone morphology of these axons as they navigate their way to visual cortex.

It was striking to find that the growth cones of LGN axons at the earliest ages (E30, E36) were more complex than those labeled at later ages (E45-60). For example, as shown in Figure
4, the growth cones of LGN axons running within the optic radiations en route to visual cortex are typically very large, about $25 \mu \mathrm{m}$ in extent, and consist of several prominent filopodia emerging from the lamellipodial body of the growth cone. Growth cones of this size and complexity were observed along the entire route of the radiations from the thalamus to visual cortex at these early ages (Fig. 5). In contrast, at later ages, when the majority of growth cones are located in the subplate rather than in the radiations, growth cone morphology is simpler (fewer filopodia) and growth cones are much smaller. This difference in morphology can be seen in Figure 6 (compare row 1, optic radiations, with rows 2 and 3, nonvisual and visual subplate). Moreover, as also evident in Figure 6, the growth cones of LGN axon collaterals in nonvisual subplate (see following section), of the parent LGN axons in visual subplate, and of LGN axons once within the cortical plate (E60) are not qualitatively different in their morphology. Therefore, the earliest thalamic axons to enter the telencephalon have particularly elaborate growth cones; axons at later ages have apparently simpler growth cones that do not undergo any major morphological changes during subsequent development.

\section{Interstitial collateral branches of $L G N$ axons}

The first DiI-labeled thalamic axons can be detected in the intermediate zone below future visual cortex by E36. At this age the first postmitotic neurons have been split into the marginal zone and subplate (Luskin and Shatz, 1985b) as the neurons of cortical layer 6 complete their migrations and insert themselves between them (Luskin and Shatz, 1985a,b). Therefore, the intermediate zone at E36 consists of subplate neurons (located in the subplate, just beneath the cortical plate), migrating neurons destined primarily for cortical layer 5 , and radial glial cell processes (Shatz and Luskin, 1986). Layer 4 neurons, the ultimate targets of LGN axons, have not yet been generated 

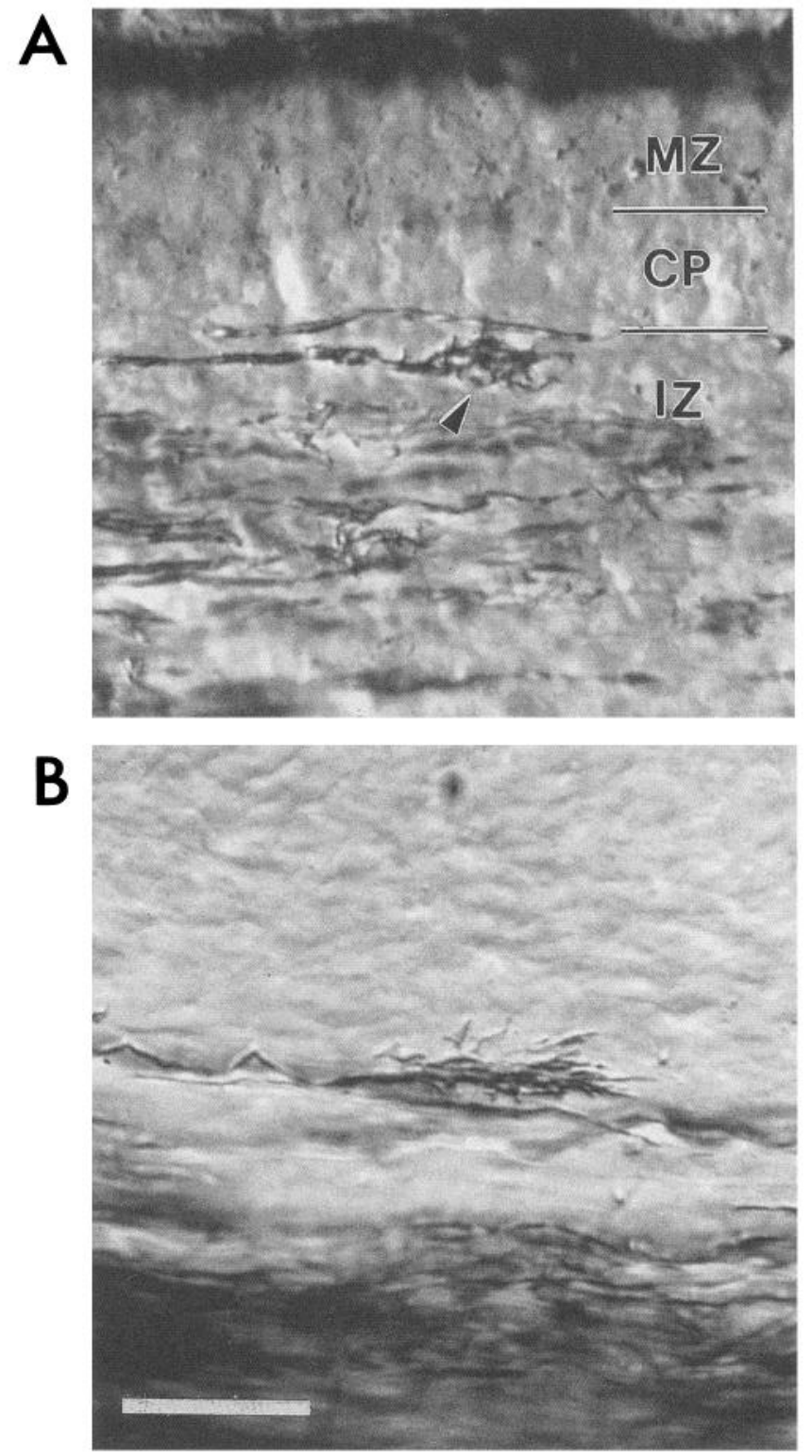

Figure 4. Growth cones of thalamic axons at E30. These DiI-labeled axons were photoconverted to precipitate a DAB reaction product and were photographed under Hoffman bright-field optics. $A$, A number of axons labeled with DiI from dorsolateral thalamus can be seen within the intermediate zone $(I Z)$ of the lateral telencephalon. The growth cone of one axon immediately below the cortical plate $(C P)$ is indicated by the arrowhead. At this early age the cortical plate consists only of the first postmitotic neurons of the telencephalon, which are destined to be subplate and marginal zone $(M Z)$ neurons. $B$, A DiI-labeled growth cone located in the internal capsule can be seen extending multiple filopodia close to a dense fascicle of axons labeled from the same thalamic injection site. Scale bar, $25 \mu \mathrm{m}$ for $A$ and $B$.

in the ventricular zone (Luskin and Shatz, 1985a). Examples of axons near visual cortex at E36 and E40 are shown in Figure 7. Upon reaching the subplate below presumptive visual cortex, most of these end in a series of simple terminal branches rather than as a single growth cone.

It was remarkable to find that LGN axons do not have simple, unbranched morphologies as they traverse past nonvisual cortical areas en route to visual cortex. Instead, as shown in Figure 8 , many give off distinct interstitial collaterals of up to $500 \mu \mathrm{m}$

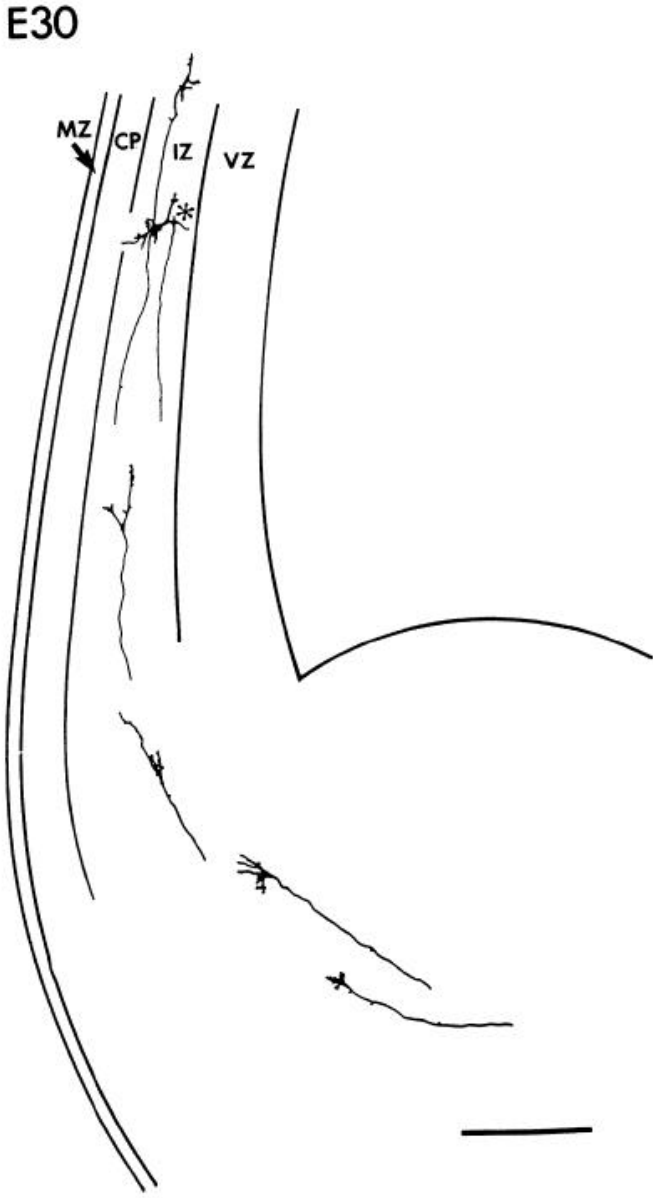

Figure 5. Camera lucida drawings of axons labeled from dorsolateral thalamus at E30 shown in a coronal section through the lateral wall of the telencephalon. These axons are restricted to the intermediate zone (IZ) of the cerebral wall, and most end in elaborate growth cones bearing large lamellipodia and several filopodia (see also Fig. 6). Note that there are no obvious differences in the complexity of growth cones at different points along this pathway. The location of a retrogradely labeled subplate neuron (asterisk) near a thalamic axon tipped by a growth cone some distance away is also shown. Both were labeled from the same thalamic injection of DiI. Dorsal is $u p$; lateral is to the left. $M Z$, marginal zone; $C P$, cortical plate; $V Z$, ventricular zone. Scale bar, $200 \mu \mathrm{m}$.

in length as they grow within the optic radiations, long before they arrive at their ultimate target. LGN axon collaterals located beneath nonvisual areas of the cortex (such as presumptive auditory cortex) are abundant between E36 and E50. As shown in Figure 9, occasionally such collaterals have higher-order branches, but they are almost always restricted to the subplate and do not appear to invade the overlying cortical plate. It is likely that thalamic axons form these collaterals quite early in their development; one can occasionally observe interstitial growth cones arising from the main trunk of thalamic axons as early as E30. Moreover, the collaterals are a transient feature of developing geniculocortical axons. To obtain an estimate of the number and frequency of these collaterals, we counted the number of collaterals emerging from the optic radiations in a series of $200-\mu \mathrm{m}$-thick DiI-labeled sections from brains between E43 and E47, and at P7. Counts were restricted to nonvisual cortex located along the lateral wall of the telencephalon (e.g., Fig. 9). (Note that this method does not provide information about the number of collaterals per LGN axon, but rather about 


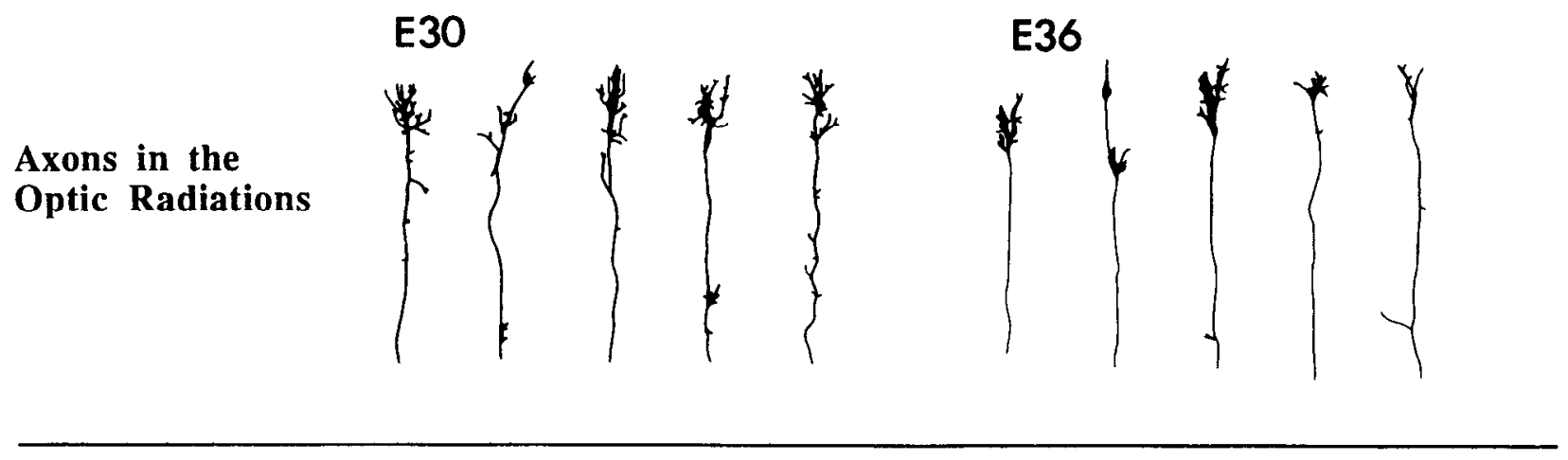

E36 E43-45
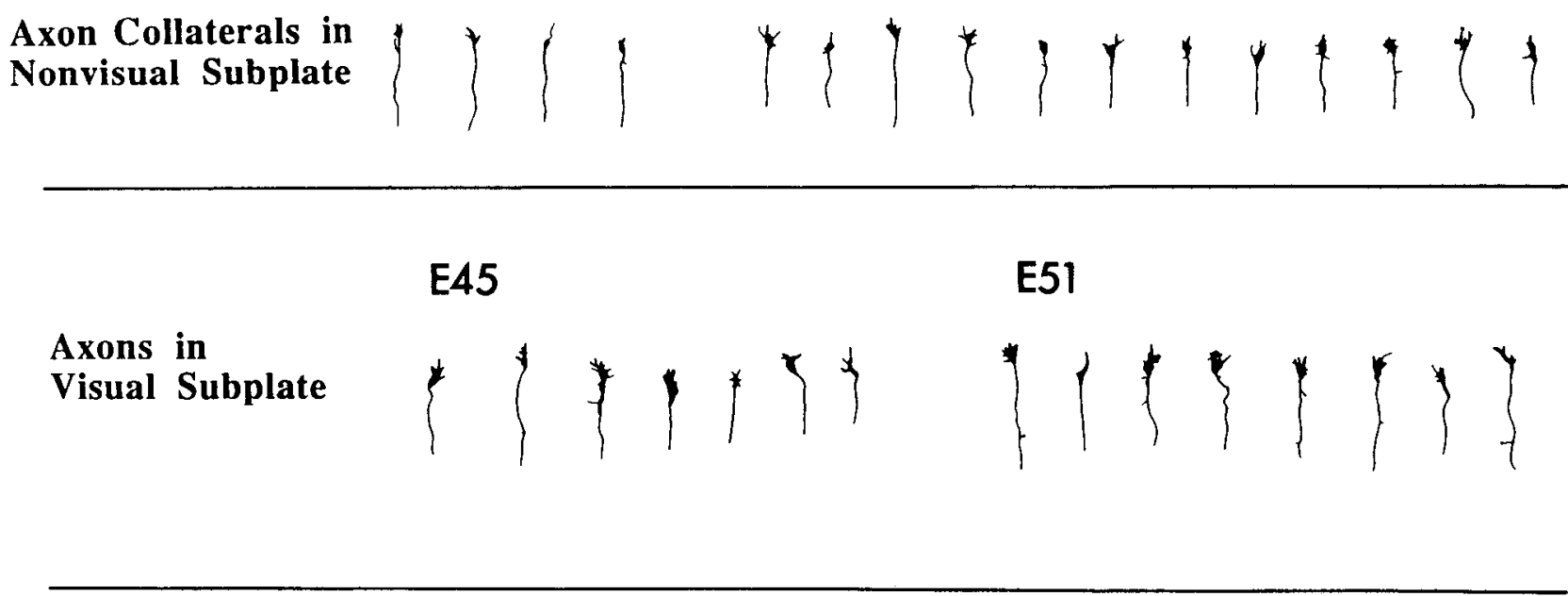

Axons in the
Cortical Plate

E60

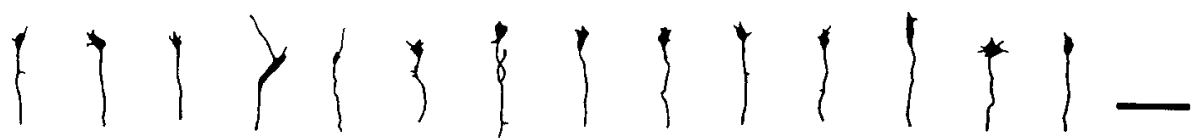

Figure 6. A comparison of growth cone morphology at different stages of LGN axon development. The growth cones of LGN axons within the optic radiations at early ages (E30, E36) are more complex than the growth cones extended in other locations and at later ages. At early ages (row 1: E30, E36), when the axons are growing within the optic radiations, LGN axon growth cones are larger and have more filopodia than at later ages, when growth cones have arrived in the visual subplate (row 3: E45, E51) or entered the cortical plate (row 4: E60). LGN axons also give off collaterals to nonvisual subplate (row 2: E36, E43-45; see text and figs. 8, 9); the growth cones of these collaterals are also smaller and simpler than those tipping the parent axon at E30 and E36. Scale bar (lower right), $25 \mu \mathrm{m}$.

the numbers emerging from the entire population of LGN axons in the optic radiations.) Between E43 and E47, there are $22 \pm$ 5 collaterals given off within the subplate per millimeter of optic radiations ( $n=17$ sections); by $\mathbf{P} 7$, LGN axons have virtually no collaterals below the corresponding cortical area. Since the counts are likely to be an underestimate (not all LGN axons extend collaterals within a given section), it is clear that a dramatic reduction of collaterals in nonvisual subplate takes place between E43 and P7.

\section{Branching of $L G N$ axons in the visual subplate}

Between E36 and E51 the majority of LGN axons terminate within the subplate beneath the visual cortex, resulting in a dense plexus of axons confined to the visual subplate (Figs. 3A, 10A).
In marked contrast to their simple morphology consisting of a single parent axon tipped with a growth cone at earlier times in development, LGN axons in the visual subplate at E51 have several terminal branches that are distributed widely (e.g., Fig. $10 B)$. Prior to E51, axons rarely if ever appear to invade the cortical plate. Examples of LGN axons branching within visual subplate are shown at F40 in Figure 7, at F45 and 51 in Figures 10 and 11, and at E61 in Figure 12. The branching within the subplate is sparse compared to the eventual dense terminal arbor formed later within layer 4 (cf. Fig. 15). Since at ages older than E43 the density of labeling makes it impossible to follow individual LGN axons over several sections, the branching we observe in the subplate in single $200 \mu \mathrm{m}$ sections represents a lower limit on the extent of branching by individual axons. Similarly, when we observe axons that do not branch in a given 

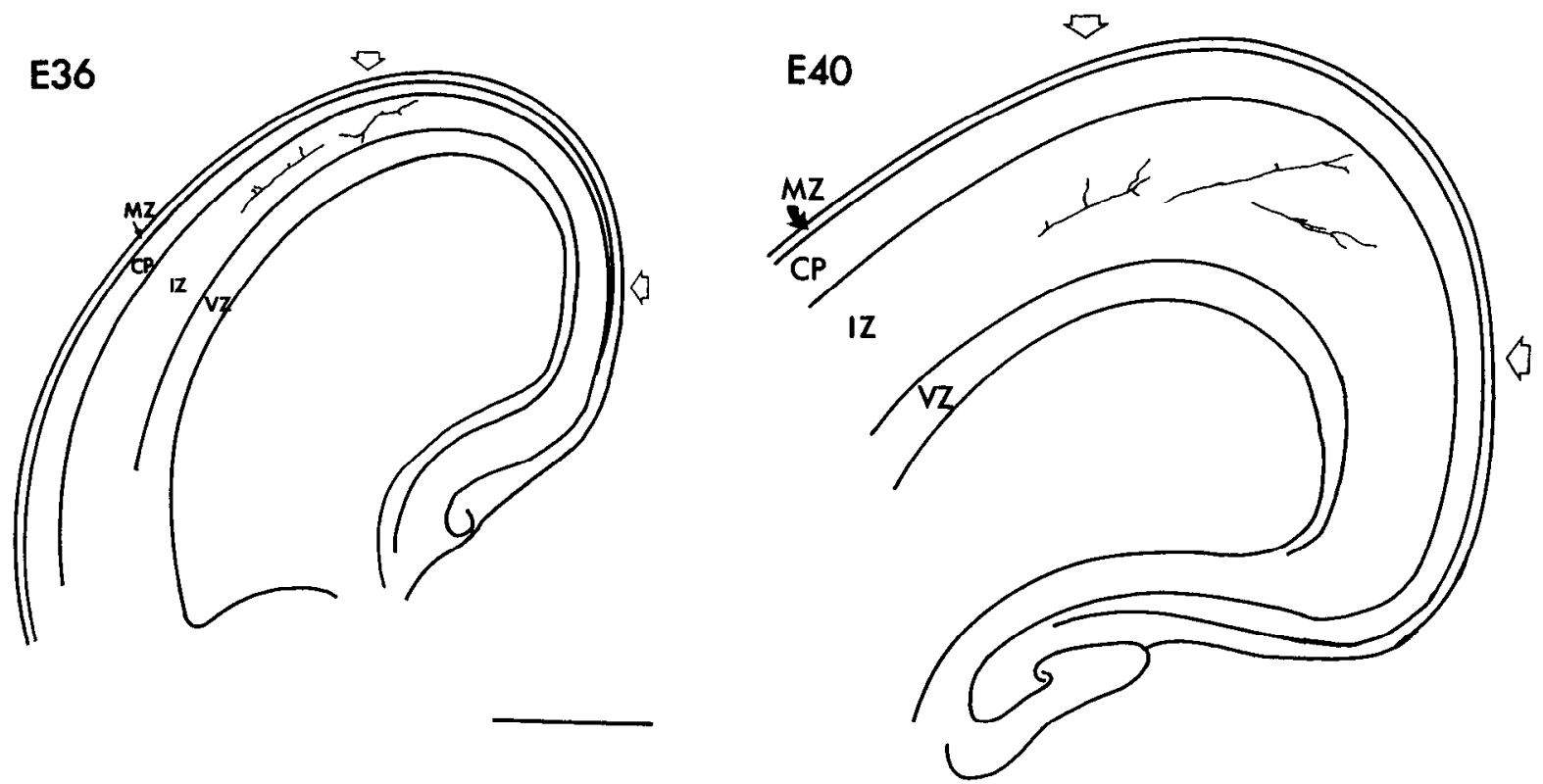

Figure 7. Camera lucida drawings of Dil-labeled LGN axons located near visual cortex at $E 36$ and $E 40$. These axons give off several collaterals usually directed toward the cortical plate. At E40 the axons frequently bifurcate beneath presumptive visual cortex and extend a few branches within the intermediate zone $(I Z)$ rather than terminating in a single leading growth cone. The location of axons indicates that they are present only within the intermediate zone and have not invaded the cortical plate $(C P)$. The region between the arrows indicates presumptive visual cortex. In Figures 7, 9, 11, and 12, lines representing axons have been thickened for clarity. $M Z$, marginal zone; $V Z$, ventricular zone. Scale bar, 1 mm.

section, we cannot rule out the possibility that they do branch in an adjacent section. However, between E36 and E43, when the density of labeled LGN axons near visual cortex is low, virtually all labeled axons do branch within the subplate, suggesting that such branching may be very common.

The most notable feature of $L G N$ axon development between E36 and E50 is the formation of a dense plexus of terminal branches within the subplate. By E51 some LGN axons can also be detected at the base of the cortical plate, as is obvious by inspection of Figure $10 C$, although an overwhelming majority are still restricted to the subplate. At this age the neurons comprising layer 4 , the primary targets of LGN axons, are still en route to the cortical plate and will not complete their migrations until about E55 (Shatz and Luskin, 1986).

\section{Ingrowth of $L G N$ axons into cortical layer 4}

By E60, LGN axons have finally arrived within layer 4 of the cortical plate. At this stage, layer 4 neurons have completed their migration and occupy the top of the cortical plate (layers 2 and 3 are still en route). The LGN axons grow through layers 6 and 5 , and some turn abruptly to run tangentially upon reaching layer 4 (Fig. 13). Other axons begin branching upon entering the cortical plate, extending simple branches both in layer 4 and the deeper cortical layers, as shown in Fig. 12 (see also Fig. 3). The axons within layer 4 frequently arise as an extension of one of the many LGN axon branches still located within the subplate (Fig. 12).

While a clear laminar restriction of terminal arbors to layer 4 is not evident at E60, LGN axons subsequently branch extensively and rapidly within layer 4 to form the basic structure of the terminal arbor by P7 (Figs. 14, 15). As can be seen in Figure 15, by the end of the first postnatal week LGN axons acquire several higher-order branches that are generally restricted to layer 4 and the base of layer 3. At least some of these axons maintain collaterals within the subplate during the first postnatal week (e.g., Fig. 14B, arrowhead in WM). Although the width (tangential extent within layer 4) of individual terminal arbors in the adult is usually less than $500 \mu \mathrm{m}$ (Ferster and LeVay, 1978), consistent with the periodicity of ocular dominance columns, individual LGN axons at P7 often branch over a larger distance within layer 4 . Some of these axons branch uniformly over a tangential extent greater than $1 \mathrm{~mm}$, as shown, for example, in Figure 15e. This observation is consistent with previous autoradiographic evidence from transneuronal transport studies that show that discrete ocular dominance columns are not visible at early postnatal ages (LeVay et al., 1978).

\section{$L G N$ axonal projection to the marginal zone}

The results presented so far demonstrate that LGN axons display distinct morphological characteristics at different stages of development of the geniculocortical projection. LGN axons arrive in the vicinity of future visual cortex as early as E36 but remain restricted to, and branch within, the subplate until about E50, when the first axons can be detected within the cortical plate. Once within the cortical plate, additional axonal branching is restricted principally to layer 4 , the ultimate terminal zone for these axons.

There is one exception to the general rule that between E36 and E50 LGN axons remain confined to the subplate and do not invade the cortical plate. As early as E40, a few axons could be traced, running into and through the cortical plate. These axons never branch within the cortical plate, but upon arriving beneath the pial surface, they make a sharp turn to run tangentially within the marginal zone. Examples of LGN axons that project to the marginal zone at E47 and P20 are shown in Figure 16. Some of these axons also give off collaterals within the subplate. The morphology of axons projecting to the marginal zone (future layer 1) remains largely unchanged over the course of development. At late prenatal and neonatal ages, however, it is possible to trace branches that arise out of one main axon 

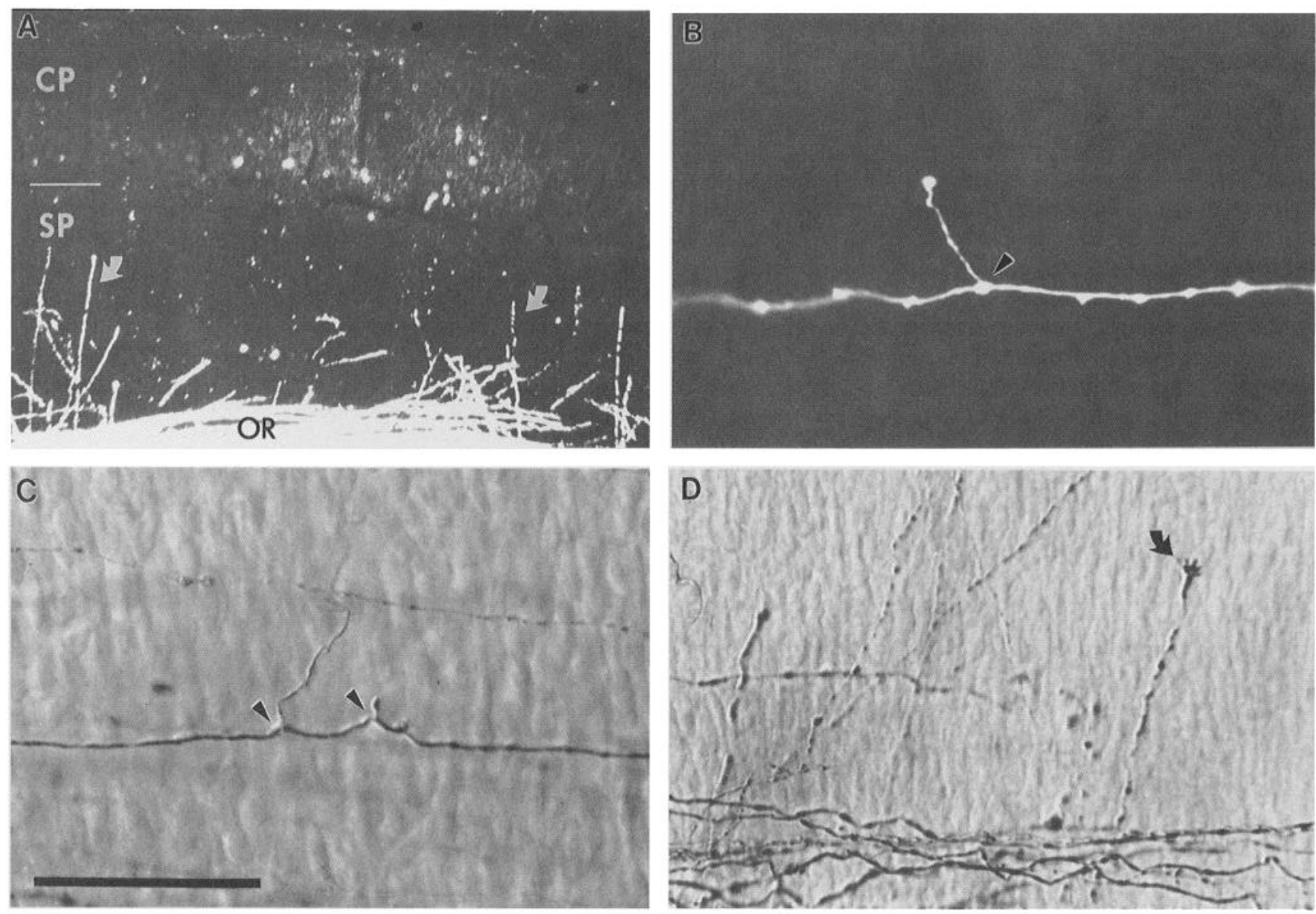

Figure 8. The morphology of LGN axons traveling beneath nonvisual areas of the lateral telencephalon en route to future visual cortex at E43 $(A, C$, and $D)$ and E50 $(B) . A$, LGN axons within the intermediate zone of the lateral telencephalon run in the optic radiations $(O R)$ as seen in dark-field optics following DAB photoconversion. Many simple axons (arrows) can also be seen emerging from the optic radiations into the subplate $(S P)$, but not entering the cortical plate $(C P) . B$ and $C$, The morphology of individual LGN axons shows that the axons given off into the subplate of lateral telencephalon are interstitial collaterals (arrowheads) of axons whose main trunks run in the optic radiations. $D$, The growth cone of an axon collateral in nonvisual subplate (arrow). Scale bar: $500 \mu \mathrm{m}$ for $A ; 50 \mu \mathrm{m}$ for $B-D$.
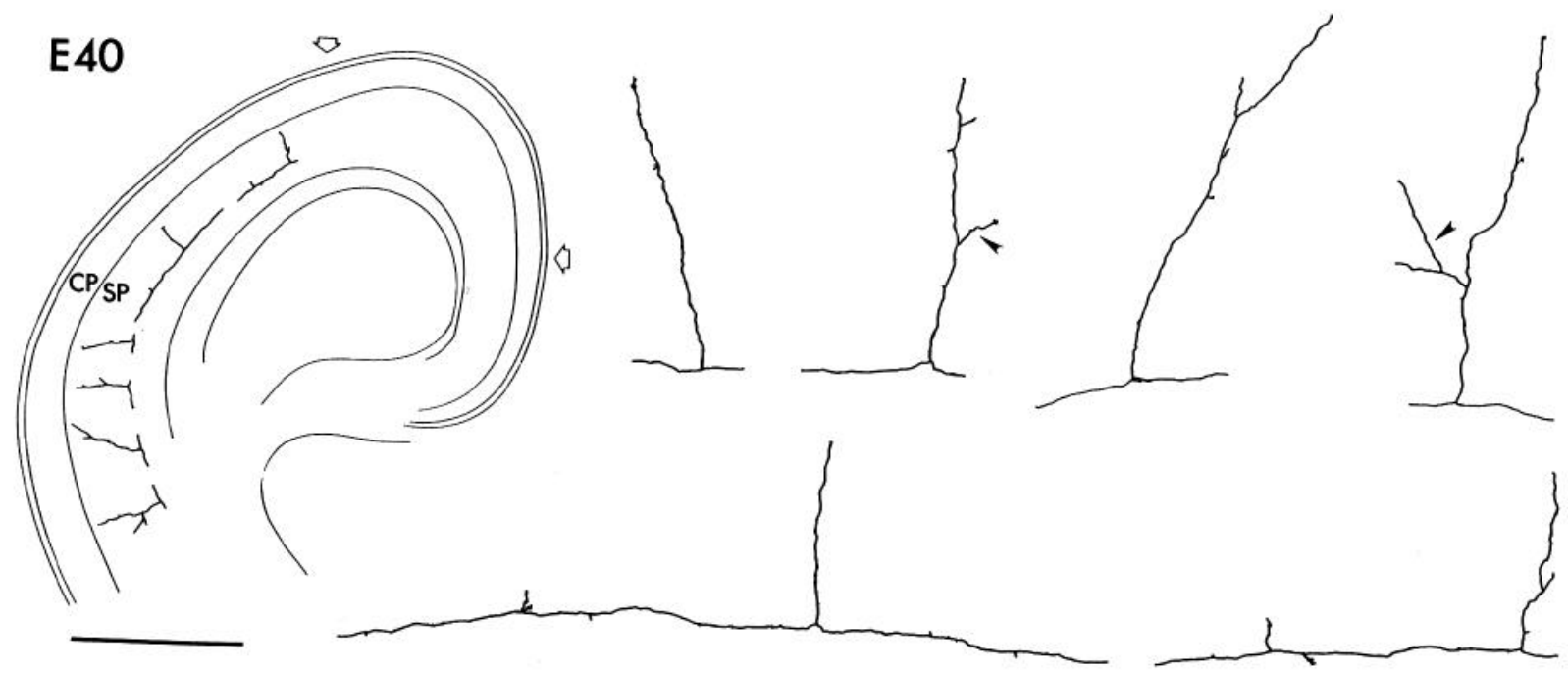

Figure 9. Camera lucida drawings of LGN axons at E40 en route to visual cortex showing that many of the LGN axons give off interstitial collaterals in nonvisual subplate below regions of lateral telencephalon far away from their final destination, visual cortex (region between arrows). These collaterals are present only in the subplate $(S P)$ and not in the cortical plate $(C P)$. Drawings of individual axons at higher magnification show that these collaterals sometimes have their own second-order branches (arrowheads). Scale bar: composite, $2 \mathrm{~mm}$; axon drawings, $350 \mu \mathrm{m}$. 

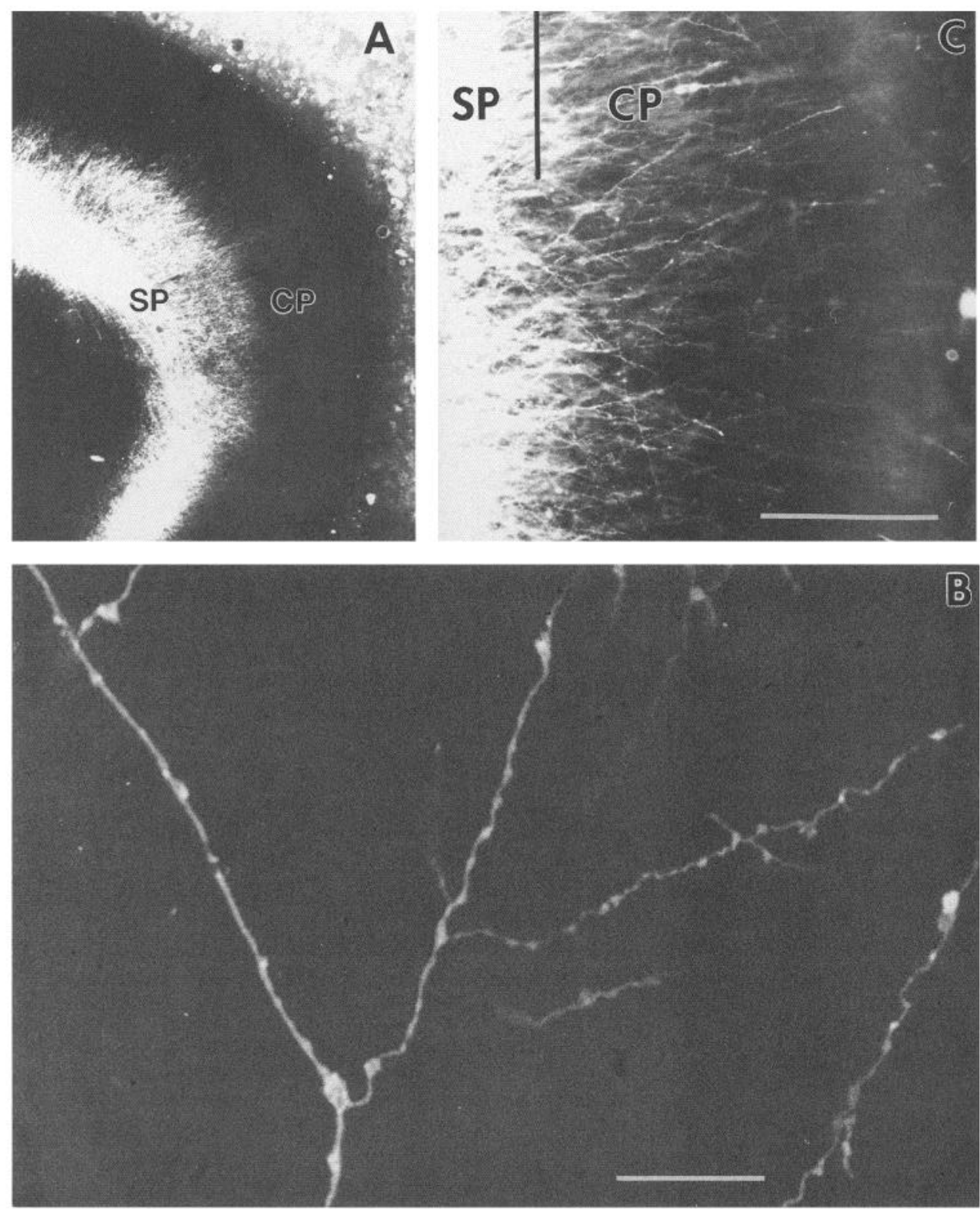

Figure 10. Distribution of LGN axons at E51. A, DiI-labeled geniculocortical axons at E51 are confined primarily to the subplate $(S P)$ below the cortical plate $(C P)$ destined to become visual cortex. Dorsal is $u p$; medial is to the right in this coronal section. $B$, Confocal microscope image of an LGN axon located in the visual subplate showing the characteristic highly branched morphology of these axons during the waiting period. $C$, Higher magnification of $A$. It is evident that at E51 a significant number of geniculocortical axons are also present within the deeper layers of the cortical plate, although the large majority of LGN axons remains restricted to the subplate. The cortical plate at this age consists of layer 5 and 6 neurons. Layer 4 neurons have not quite completed their migrations. Scale bars: $A$ (shown in $C$ ), $1 \mathrm{~mm} ; B, 50 \mu \mathrm{m}$; $C, 250 \mu \mathrm{m}$.

trunk in the white matter to the same terminal location within layer 1 (see composite camera lucida drawing in Fig. 12). In general, these axons traverse long distances within layer 1 without forming any second-order branches. Thus, there is a small subpopulation of LGN axons that project to the marginal zone during development, an observation consistent with previous autoradiographic labeling studies showing a geniculocortical projection to the marginal zone (Shatz and Luskin, 1986).

\section{Discussion}

In this study, we have used the lipophilic tracer DiI to chart the morphological changes undergone by individual LGN axons during the development of geniculocortical connections from the time axons enter the telencephalon to the time they arrive within cortical layer 4 , their ultimate target. By examining the morphology of individual LGN axons, we have confirmed and extended current knowledge of the development of this system obtained previously by the indirect autoradiographic labeling technique of transneuronal transport following intraocular injections of ${ }^{3} \mathrm{H}$-amino acids (Rakic, 1977; LeVay et al., 1978; Shatz and Luskin, 1986). The results of those studies permitted the drawing of a broad outline of the time course of axon development, consisting of four basic phases of growth: (1) axon elongation toward visual cortex; (2) the "waiting" period, in which newly arriving axons accumulate in the visual subplate; (3) a period of axon ingrowth into the cortical plate; and finally, (4) axon segregation to form the system of ocular dominance columns within layer 4 .

The results of the present study can now add to this basic outline essential temporal and morphological details, some of which are summarized diagrammatically in Figure 17. A major finding is that LGN axons exhibit considerable morphological complexity even before they grow into cortical layer 4 to elaborate a mature terminal arbor. Early LGN axons growing within the intermediate zone of the telencephalon en route to visual cortex do not just follow straight unbranched trajectories, but 

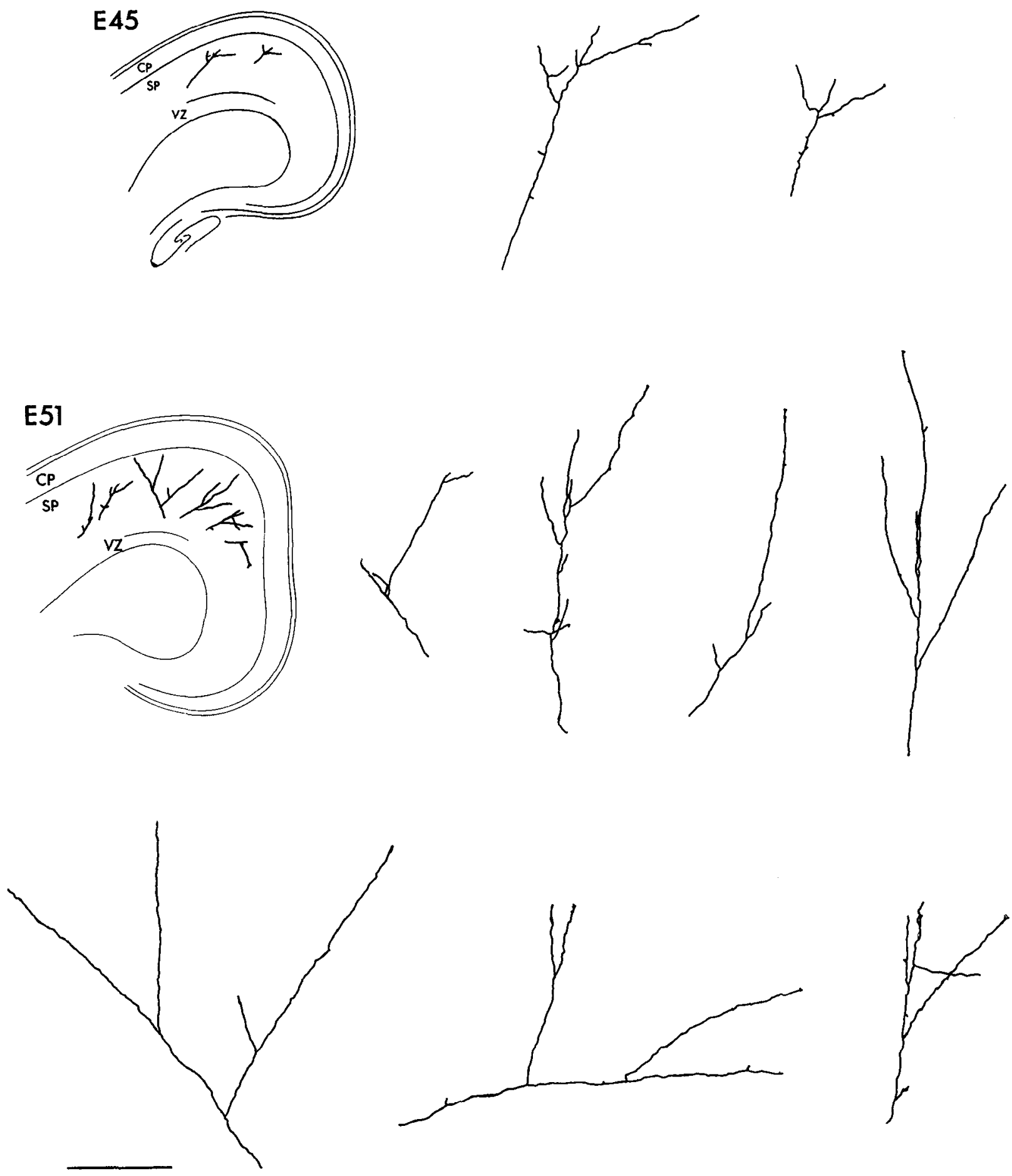

Figure 11. Morphology of LGN axons within the subplate (SP) at E45 and E51. The composite drawings at each age show the location of LGN axons within the cerebral wall. Many of the axons branch in the subplate below visual cortex. At higher magnification (right), it is apparent that many of the axons have higher-order branches that probably account for the dense plexus of labeled profiles seen within the subplate at these ages (cf. Figs. 3, 10). $C P$, cortical plate; $V Z$, ventricular zone. Scale har: composite, $2 \mathrm{~mm}$; axon drawings, $400 \mu \mathrm{m}$.

rather periodically send out transient collaterals, tipped with growth cones, into the overlying subplate. Moreover, once the growth cones of LGN axons arrive within the vicinity of future visual cortex, they do not simply "pause" or "wait," as previously inferred from autoradiographic labeling studies (Rakic, 1977; Shatz and Iuskin, 1986), but instead elaborate a series of simple long branches, almost all of which are confined to the subplate immediately below visual cortex. These observations imply that the process of formation of geniculocortical connec- tions is a dynamic one, involving extensive interactions not only during axon elongation but also once the growth cones have arrived within the subplate beneath visual cortex.

\section{A reevaluation of the waiting period for} geniculocortical axons

Many previous studies using autoradiographic tracing techniques in several different species have shown that a number of axonal systems (thalamocortical, callosal) accumulate and "wait" 
E60

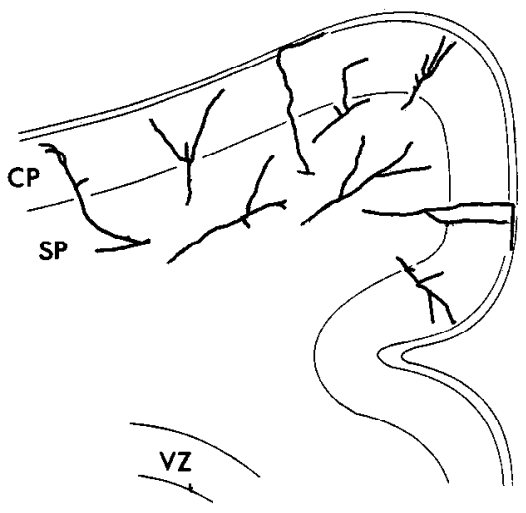

$M Z$

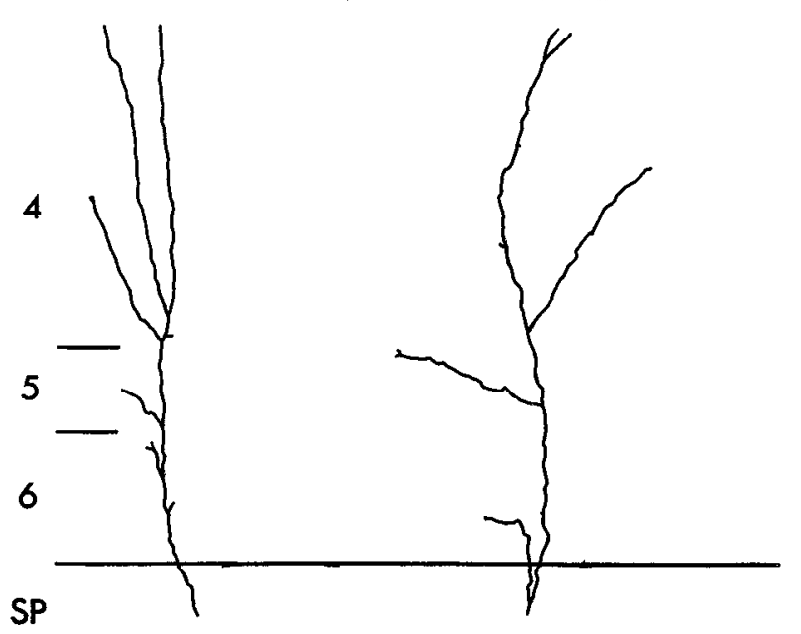

$M Z$

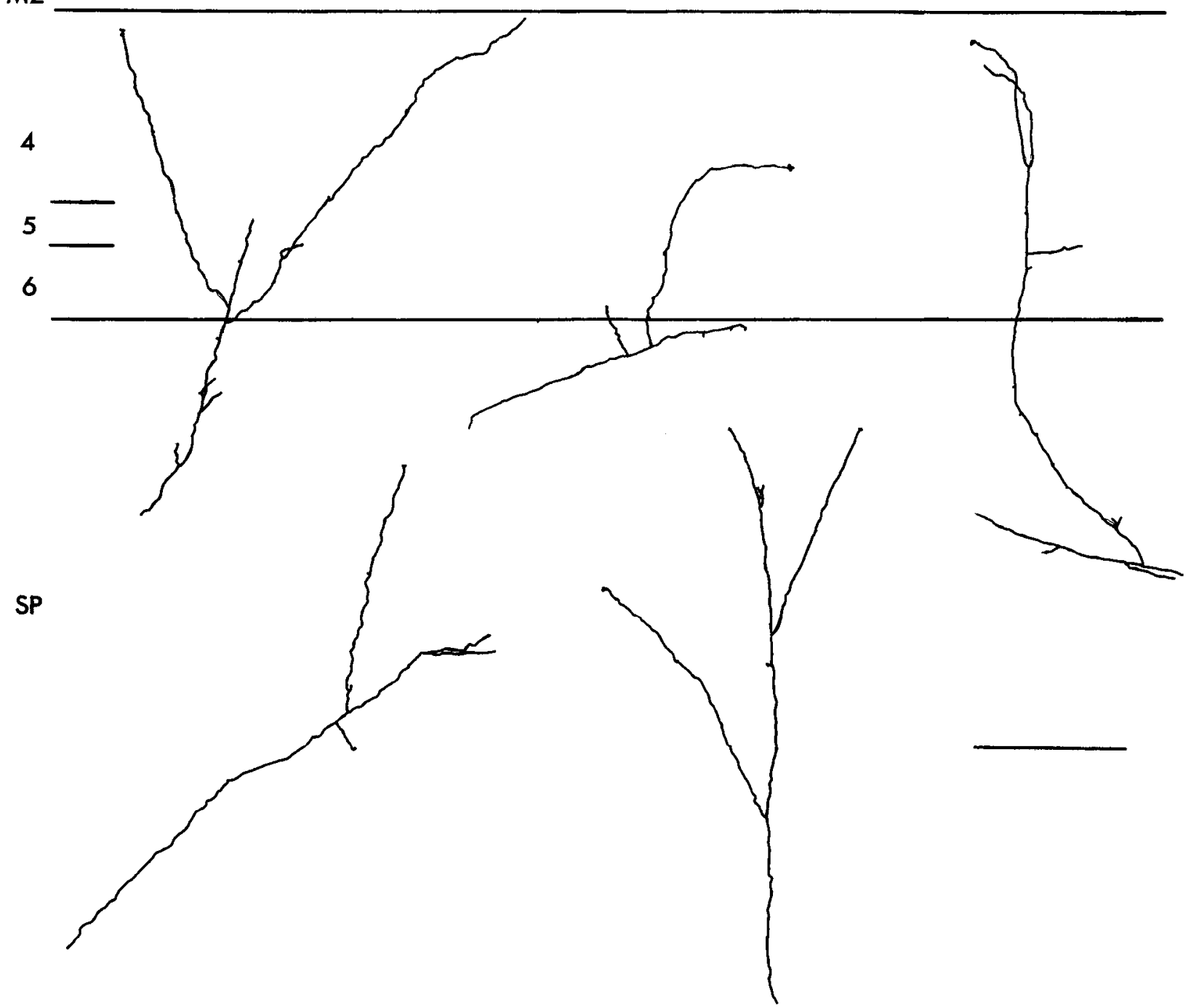

Figure 12. Distribution and morphology of LGN axons at E60. The composite drawing (upper left) shows that at E60 LGN axons are present in the subplate $(S P)$, the cortical plate $(C P)$, and the marginal zone $(M Z)$. Higher-magnification drawings of individual axons show that within the cortical plate LGN axons branch primarily within layer 4, although they often extend collaterals within layers 6 and 5. (Occasionally axons transverse the cortical plate unbranched to reach the marginal zone, two are shown in the composite drawing; see also Fig. 16.) VZ, ventricular zone. Scale bar: composite, $2 \mathrm{~mm}$; axon drawings, $225 \mu \mathrm{m}$ (top) and $300 \mu \mathrm{m}($ bottom). 

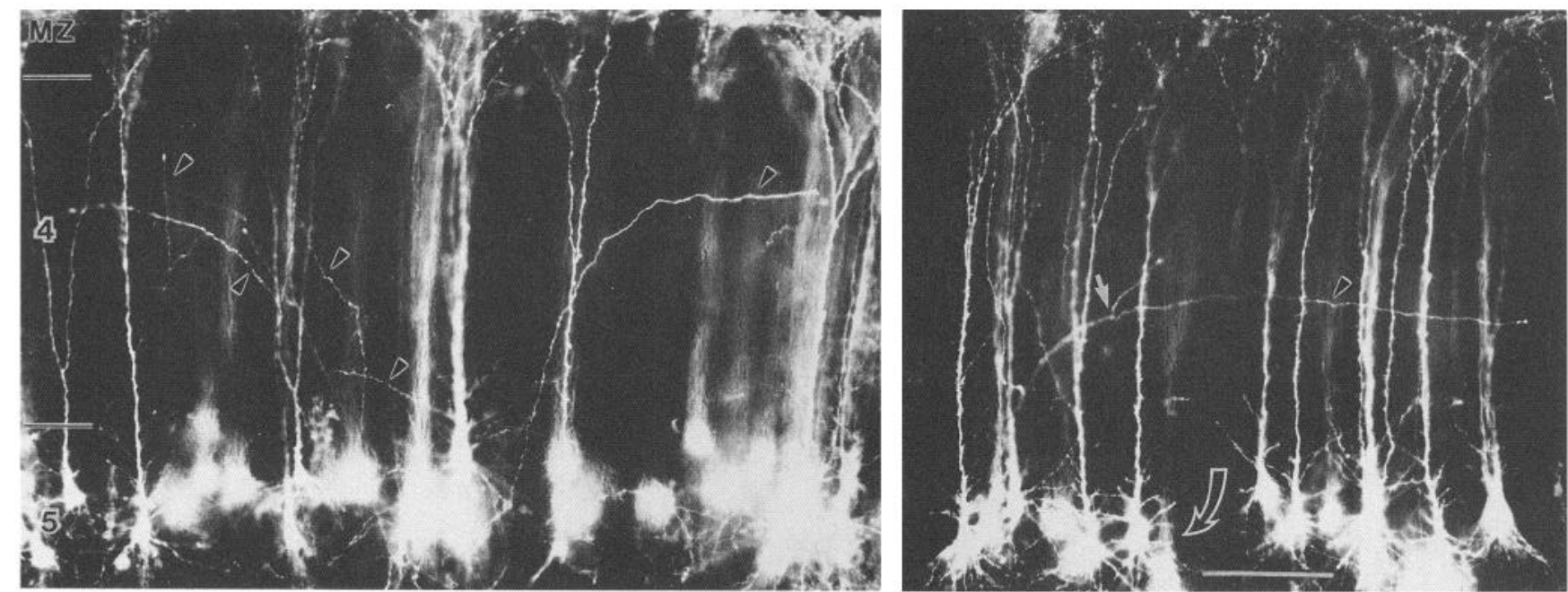

Figure 13. LGN axons are present in layer 4 at E60. Upon entering the cortical plate, and having grown past layers 6 and 5, some LGN axons turn (arrowheads) to run tangentially within layer 4 and occasionally give off second-order branches (straight arrow). Layer 5 cortical neurons are also retrogradely labeled (curved arrow) in these sections, presumably because their axons en route to the superior colliculus travel close to the injection site in the LGN. Since layer $2 / 3$ neurons are not yet postmigratory (Shatz and Luskin, 1986), layer 4 extends all the way to the marginal zone $(M Z)$. Scale bar (shown in right panel), $125 \mu \mathrm{m}$.

in the subplate before growing into the cortical plate (Rakic, 1977; Wise and Jones, 1978; Innocenti, 1981; Shatz and Luskin, 1986; for review, see Shatz et al., 1988). Recently, the application of rhodamine isothiocyanate for anterograde tracing and the DiI labeling technique in the study of the development of afferent axonal input to the cerebellum and cortex has prompted a reevaluation of the waiting period in some systems. These more sensitive tracers have revealed that climbing fiber axons invade the Purkinje cell anlage much earlier than previously detected using autoradiographic techniques, thereby potentially invalidating a previously defined waiting period (Mason et al., 1990). Similarly, there does not appear to be a pronounced waiting period during the development of thalamocortical axons in the rodent somatosensory system (Catalano et al., 1991). The use of DiI in our study, too, has required a resetting of the time when LGN axons leave the subplate and enter the deeper layers of the cortical plate from E55 (Shatz and Luskin, 1986) to E50. However, this superior labeling technique has also permitted us to set the time of arrival of the first LGN growth cones beneath the visual cortex at E36 rather than E40. Thus, the period between the time of arrival of the first LGN axons within visual subplate, and the time when appreciable numbers of axons are present in the deeper cortical layers, is about 2 weeks long in the cat geniculocortical system, leaving no doubt as to the existence of a significant period during which the majority of LGN axons dwell within the subplate. One reason for a more prolonged waiting period in higher mammals as compared to rodents may be that there is a much larger discrepancy in timing between arrival of ingrowing thalamic axons and the migration of their target layer 4 neurons to the cortical plate in cats and monkeys. Consistent with this interpretation is the observation that rodent geniculocortical axons appear to arrive within layer 6 bjust as layer 4 neurons complete their migration to the cortical plate (Reinoso and O'Leary, 1990; see also Lund and Mustari, 1977). Thus, in rodents there is no requirement for thalamic axons to wait since their cortical target neurons are essentially in position when the axons arrive.
The finding here that LGN axons within the subplate branch over rather extensive territory is remarkable, and requires a reconsideration of the choice of the term "waiting" period or "waiting" compartment (Rakic, 1977; used in reference to the subplate zone in which the axons accumulate). Plainly, the word "wait" is somewhat misleading, since it connotes a pause in forward progress or a lack of activity or movement, in which case one might have perhaps expected to find unbranched axons tipped with growth cones as described in the development of the peripheral projections of motor neurons (Tosney and Landmesser, 1985b). On the contrary, LGN axons once within visual subplate begin to elaborate branches, suggesting that a more active process than a "wait" is taking place. As discussed below, the axons branch within a zone also filled with subplate neurons and many synapses (for reviews, see Shatz et al., 1988, 1990), implying that they may be involved in ongoing dynamic interactions during this 2 week period. Since the term "waiting period" is now so pervasive in the literature, it is probably pointless to suggest an alternative, but the lesson here is that the connotation may be quite misleading, at least in higher mammals such as cat or primate where the period is of considerable duration.

As mentioned in Results and noted previously (Shatz and Luskin, 1986), not all LGN axons are confined to the subplate during the waiting period, but rather a small group appears to reside in the marginal zone. It may be that this particular group of axons arises from neurons belonging to the future C-layers of the LGN: such axons are known to be present in layer 1 of neonatal kittens (LeVay et al., 1978; Kato et al., 1984; Shatz and Luskin, 1986). Here, DiI labeling has revealed a further important piece of morphological information: these axons, as they traverse the cortical plate, are absolutely smooth and unbranched. Only within the subplate, or occasionally again when the axons enter the marginal zone, do they branch. Thus, early in development, few if any geniculocortical axons arborize within the cortical plate itself. Rather, they are confined to the subplate or marginal zone. 

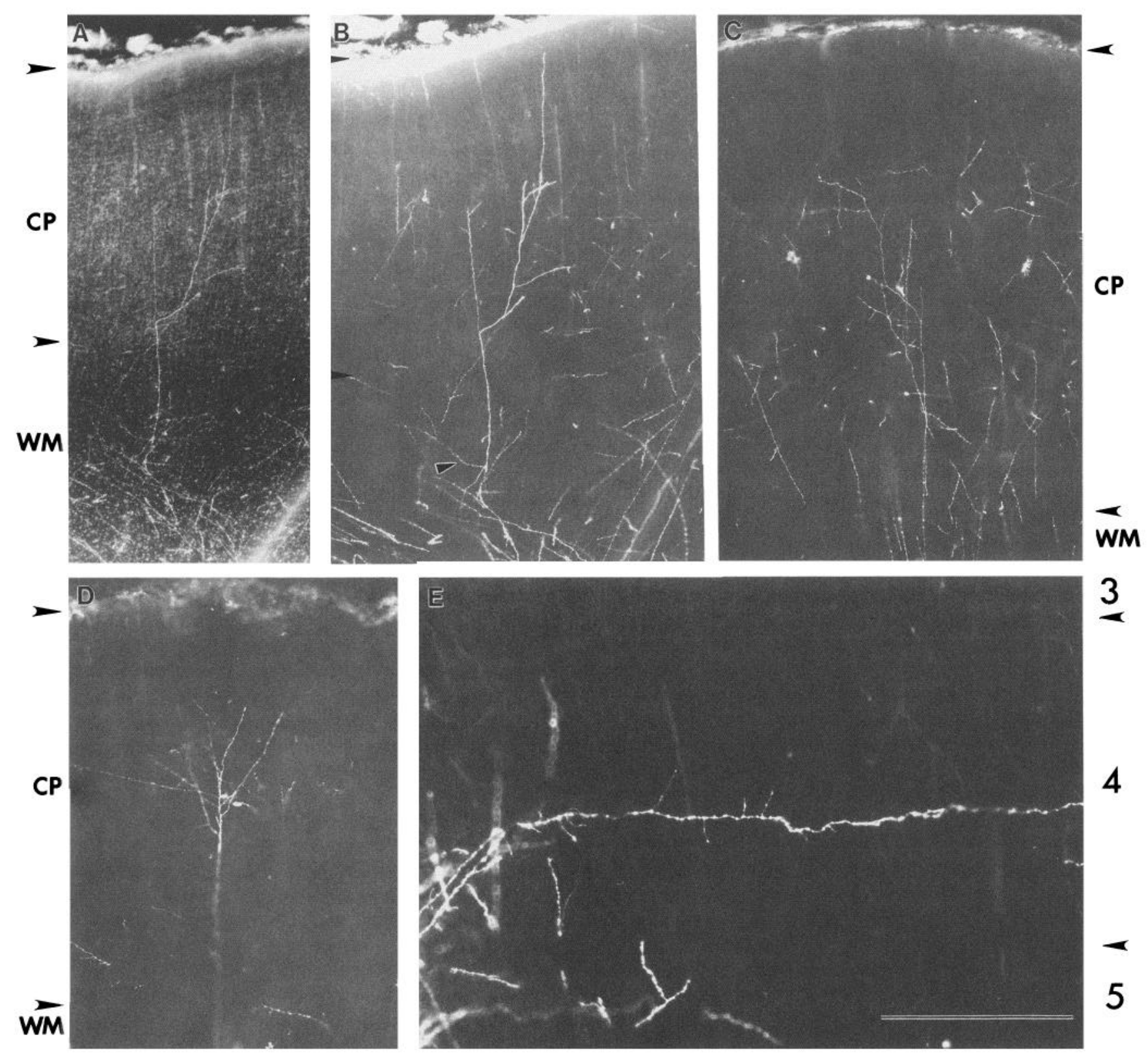

Figure 14. Photographs of DiI-labeled LGN axons branching within the cortical plate $(C P)$ at P7. $A$, The extent of the cortical plate with respect to the LGN axon is shown in this double exposure (rhodamine/fluorescence) by counterstaining the section containing the DiI-labeled axons with MPD, a green fluorescent Nissl stain. $B$. The DiI-labeled axon shown in $A$ (viewed under rhodamine fluorescence only) branches primarily in layers 4 and 6, but also has a branch in the subplate (arrowhead in $W M$ ) and one that reaches the marginal zone. $C$ and $D$, DiI-labeled LGN axons branch extensively within the cortical plate. (A camera lucida drawing of the axon in $D$ is shown in Fig. $15 b$.) $E$, An LGN axon runs tangentially within layer 4 , giving off several short collaterals but no well defined terminal arbor. $W M$, white matter. In $A-D$, the extent of $C P$ is 1.2 mm; scale bar in $E, 200 \mu \mathrm{m}$.

\section{Logistics of geniculocortical development}

As early as E26, DiI tracings show that axons have left the region of the future LGN. By E30 they have traveled through the internal capsule and entered the telencephalon. ${ }^{3} \mathrm{H}$-thymidine birthdating studies have shown that the LGN neurons themselves are generated between about E21 and E31 (Hickey and Hitchcock, 1984), and the earliest-born neurons have completed their migrations to form the anlage of the LGN by about E30 (Shatz, 1983). Thus, LGN neurons begin to elaborate their axonal projections to the cerebral cortex immediately following (if not before) the completion of migration. This strategy would seem to be designed nicely to ensure that long-distance connections are formed as early as possible, when problems of pathfinding and target selection may be at a minimum.

The observation that the earliest (E30, E36) growth cones of LGN axons have highly complex filopodial extensions and are significantly larger than those from later ages (E45-60) is very reminiscent of studies of the developing invertebrate nervous system and chick spinal cord in which the growth cones of neurons whose axons are the first to traverse territory en route to a target ("pioneer" neurons) are more elaborate than those following later on (Bate, 1976; Bentley and Keshishian, 1982; Ho and Goodman, 1982; Yaginuma et al., 1991). Since filopodia 
Figure 15. Camera lucida drawings of LGN axon terminals within the cortical plate $(C P)$ at P7. At this age, highly branched terminals are restricted primarily to layer 4 of cortex. Some axons also have branches at the base of layer $3(a, c, d)$ within layer $6(c)$, and occasionally in the subplate (not shown). Note that the axon terminal shown in $e$ branches fairly uniformly over a tangential extent of about $1 \mathrm{~mm}$, which is twice the width of an ocular dominance column in the adult. Scale bar: composite, $3 \mathrm{~mm}$; axon drawings, $400 \mu \mathrm{m}$.
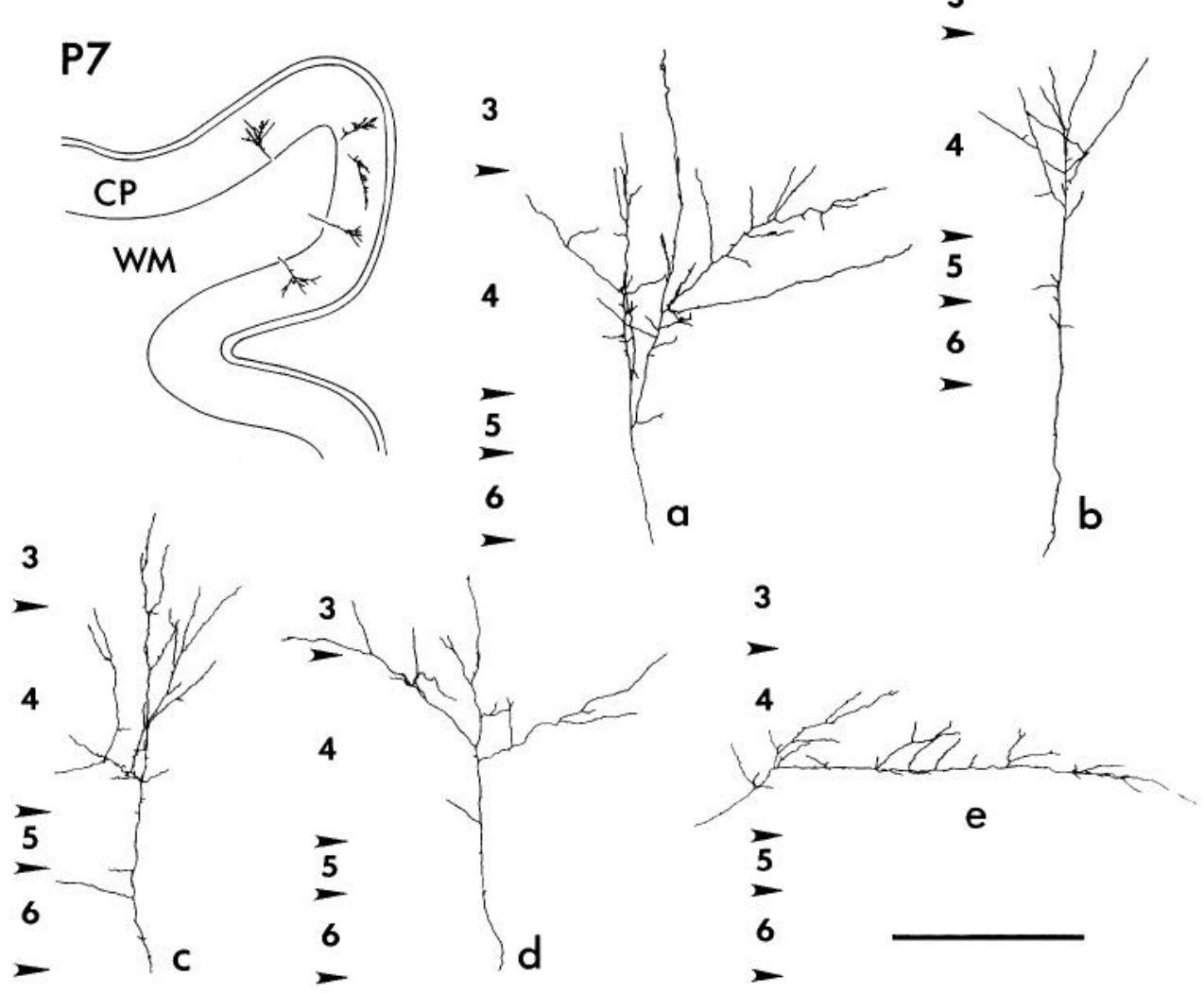

have been specifically implicated in axon pathfinding (Bentley and Toroian-Raymond, 1986), this observation may reflect a particularly specialized capacity of early thalamic axons to navigate their way to their cortical targets. We have also recently made similar observations on the growth cones of subplate neurons, which are known to pioneer the first axonal pathway from the cortex through the internal capsule to the thalamus (McConnell et al., 1989). Subplate neuron growth cones are more complex than those of the cortical neurons in layers 5 and 6 ,

whose axons form the later, stable adult descending pathway (Kim et al., 1991). These considerations raise the possibility that the first LGN axons to traverse the intermediate zone of the telencephalon en route to visual cortex may also "pioneer" their pathway, in the sense that no other ascending axonal system is already in the same place. While it is commonly assumed that the first ascending axonal systems to enter the telencephalon arise from the neurons of the basal forebrain (cholinergic) system and/or from the dopaminergic midbrain raphe nucleus (Mol-

E47

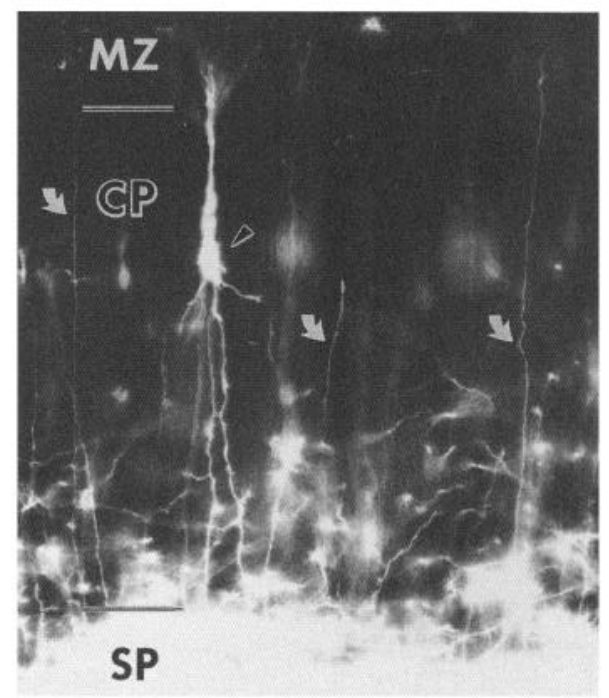

\section{P20}

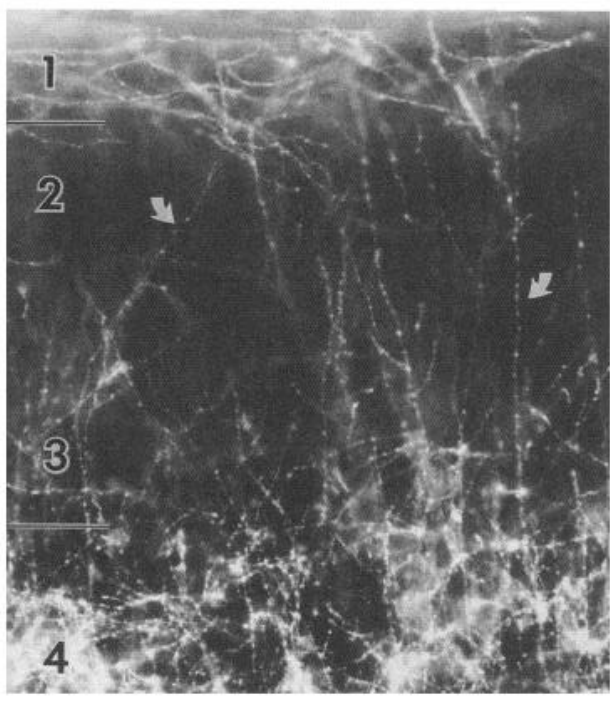

Figure 16. A subpopulation of LGN axons projects to the marginal zone $(M Z)$. LGN axons at E47 and P20 (curved arrows) can be seen growing through the cortical plate $(C P)$ to the marginal zone (called layer $l$ postnatally). These axons usually have no branches within the cortical plate. A retrogradely labeled pyramidal neuron extending a dendrite to the marginal zone can also be seen at E47 (arrowhead). SP, subplate. Scale bars: E47, $100 \mu \mathrm{m} ; P 20,125 \mu \mathrm{m}$. 
E36

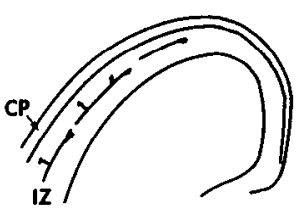

E42

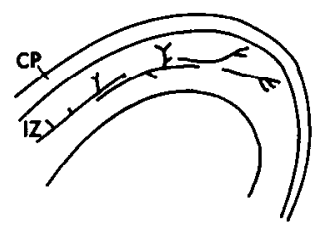

E50

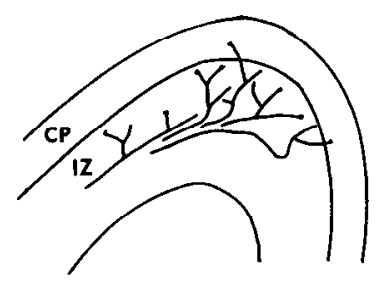

E60

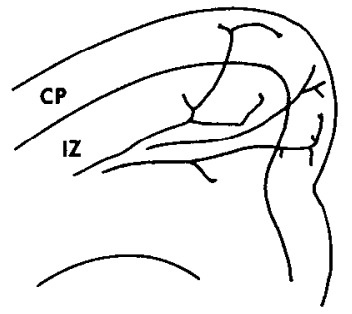

P7

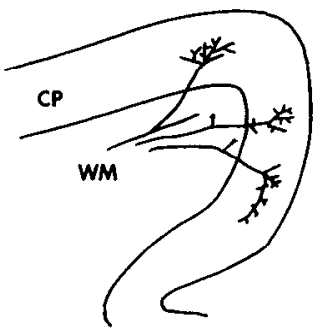

Figure 17. A cartoon summary of LGN axon development in the cat visual system based on anterograde tracing with DiI. (The rare marginal zone axons are not shown.) Growth cones arrive within the vicinity of future visual cortex by $E 36$. Between $E 36$ and $E 50$ they accumulate and branch within the subplate; the first axons can be detected within the deep cortical layers at $E 50$. By $E 60$, LGN axons are present within layer 4 , where they begin to form terminal arbors that acquire some complexity by P7. (Ocular dominance columns do not begin to form until approximately 2 weeks later.) At $E 36$, the cortical plate $(C P)$ consists only of layer 6 neurons; at $E 42$ and $E 50$, of layers 5 and 6 ; at $E 60$, of layers $4-6$; and at $P 7$, of layers 3-6. Layer 2 neurons do not complete their migration until the second postnatal week. $I Z$, intermediate zone; $W M$, white matter.

liver et al., 1973; Kostovic and Molliver, 1974; Kostovic and Rakic, 1984), it is worth noting that this assumption is based on indirect evidence from histofluorescence for monoamines, histochemistry for AChE, or Golgi impregnations. The possibility remains that pioneer axonal systems intrinsic to the telencephalon such as those now known to arise from the earliestgenerated neurons of the cortex, the neurons of the subplate and marginal zones (McConnell et al., 1989; Shatz et al., 1990), are responsible for such early intracortical axon pathways. It would be of great interest to reexamine these issues using the DiI labeling technique to reveal the ascending pathways from midbrain and basal forebrain directly, in order to establish definitively which ascending axonal systems arrive within telencephalon first.

Concurrent with the development of the geniculocortical pathway, subplate neurons are elaborating their axonal pathway toward the thalamus so that, by E30, subplate axons from the region of future visual cortex have also traversed the internal capsule en route to the LGN (McConnell et al., 1989). DiI labeling has shown that both axon pathways are located within the intermediate zone just above the ventricular zone, raising the possibility that early growth cones from subplate neurons and LGN axons may actually meet within the internal capsule at about E30 and then fasciculate with each other at later times. Such a suggestion must await direct confirmation by means of dual labeling and electron microscopy, but if it proves true, then the simultaneous formation of these two reciprocal pathways might considerably simplify the process of cortical target selection by thalamic axons.

As LGN axons elongate toward visual cortex, many of them extend collaterals, which appear to be lost later, into the subplate of nonvisual areas. Since a large fraction of LGN axons have collaterals at early ages, it is perhaps more likely that these collaterals disappear by selective remodeling/retraction rather than by cell death in the LGN. These collaterals are reminiscent of those that transiently extend from geniculocortical axons near visual subplate (Naegele et al., 1988) and from optic tract axons into the ventrobasal thalamus (I angdon and Frost, 1991) during development of the hamster visual system. While it is conceivable that such collaterals may not find suitable cellular substrates in nonvisual areas, we consider it more likely that these collaterals participate in interactions that are important for target selection by LGN axons. For example, we found that at E36 many LGN axons had collaterals in putative auditory subplate at a time when axons from the MGN have also accumulated in the same region. Since the MGN axons arrive in the auditory subplate before the LGN axons pass by en route to visual cortex (A. Ghosh and C. J. Shatz, unpublished observation), these latergrowing LGN axons may be prevented from occupying auditory subplate due to competitive interactions between the growth cones of auditory and visual thalamic axons within the subplate. In this context it would be important to know whether, in the absence of MGN axons, LGN axons can invade auditory cortex.

In contrast to the early genesis of LGN and subplate neurons, the neurons of cortical layer 4 in the cat are generated between E38 and E43 (Luskin and Shatz, 1985a), after the first LGN axons have already arrived within the visual subplate. By about E55, layer 4 neurons have migrated into position above earlier formed layers 5 and 6 (Shatz and Luskin, 1986). The route of their migration through the subplate brings layer 4 neurons into close proximity with the accumulating LGN axons, raising the possibility that the axons and layer 4 neurons may interact with each other in some way during this time. While there is no clear evidence favoring this suggestion at present, the fact that we have seen LGN axons begin to enter the deep cortical layers by E50, and to arrive within layer 4 between E55 and E60, suggests that the presence of layer 4 neurons may somehow signal the end of the "waiting" period. This temporal relationship is similar to that described in the development of the rodent geniculocortical projection (Reinoso and O'Leary, 1990).

Between E60 and P7, LGN axons undergo a rapid growth of terminal arbors within layer 4 and branch more extensively than at any time during their previous period within the subplate. Such a selective elaboration of terminal arbors within layer 4 once the axons enter the cortical plate has also been reported in hamsters (Naegele et al., 1988) and primates (Florence and Casagrande, 1990). At the same time, fewer LGN axons maintain branches within the subplate, suggesting that there is a concurrent loss of branches in this zone. By P7, some LGN axons have terminal arbors within layer 4 that branch rather uniformly and can extend tangentially over distances greater than $1 \mathrm{~mm}$. The size and morphology of some of these axons resemble the one Golgi-impregnated LGN axon at P17 illustrated by LeVay and Stryker (1979). Since the width of LGN terminal arbors within layer 4 is about $500 \mu \mathrm{m}$ in the adult (Ferster and LeVay, 1978; Gilbert and Wiesel, 1979; Humphrey et al., 1985a,b), corresponding to the width of one ocular dominance column in the cat (Shatz et al., 1977), some of these 
axons must undergo considerable remodeling and/or differential growth to achieve their adult morphology. However, other axons have restricted terminal arbors of less than $500 \mu \mathrm{m}$ in tangential extent; these axons may remain restricted during ensuing development or may also grow and remodel. We had hoped to examine these issues directly over the ensuing few weeks, but were disappointed to discover that the DiI labeling of axons from the LGN does not work well beyond early postnatal ages.

\section{Interactions between LGN axons and subplate neurons}

A major goal of this study was to examine the morphology of individual LGN axons during the period when axons accumulate within the subplate, in order to learn more about possible interactions between LGN axons and subplate neurons. During this period in the cat (E36-50), subplate neurons become highly mature morphologically and histochemically (Chun et al., 1987; Wahle and Meyer, 1987; Chun and Shatz, 1989a). The subplate zone itself is a synaptic neuropil (Kostovic and Molliver, 1974; Cragg, 1975; Chun and Shatz, 1988), with some synapses made onto subplate neurons (Chun et al., 1987). Intracellular microelectrode recordings from subplate neurons in cortical slices indicate that some of the synapses are functional, since electrical stimulation of the intermediate zone in the region of the optic radiations can elicit monosynaptic EPSPs in subplate neurons (Friauf et al., 1990). These observations, taken in conjunction with the results of the present study showing that LGN axons extend many long branches within the visual subplate, suggest that LGN axons may supply at least some of the synaptic inputs to subplate neurons. We have recently obtained evidence in favor of this suggestion by filling thalamic axons with phaseolus vulgaris leucoagglutinin and examining them at the electron microscope level (Herrmann et al., 1991).

Although the detailed nature of the interactions between LGN axons and subplate neurons remains a mystery at present, recent experiments confirm the suggestion that subplate neurons are needed for the normal development of geniculocortical connections. If visual subplate neurons are ablated at E42, soon after the onset of the waiting period, LGN axons fail to stop beneath visual cortex and at subsequent times remain confined within the white matter, instead of invading the cortical plate (Ghosh et al., 1990). Thus, LGN axons may require subplate neurons to sclect and invade their appropriate target area. In this context the collaterals given off along the course of LGN axons early in their traverse across the intermediate zone toward visual cortex may also indicate the presence of active interactions between LGN axons and subplate neurons belonging to nonvisual cortical areas. Thus, it may be that the early sequence of morphological changes seen in LGN axons prior to the time they invade the visual cortex and assume their final position within layer 4 is controlled by a set of interactions with subplate neurons that subserve the essential processes of pathfinding and cortical target selection.

\section{References}

Anderson PA, Olavarria J, Van Sluyters RC (1988) The overall pattern of ocular dominance bands in the cat visual cortex. J Neurosci 8: 2183-2200.

Bate CM (1976) Pioneer neurons in an insect embryo. Nature 260: 54-56.

Bentley D, Keshishian H (1982) Pathfinding by peripheral pioneer neurons in grasshoppers. Science 218:1082-1088.
Bentlcy D, Toroian-Raymond A (1986) Disoriented pathfinding by pioneer neurone growth cones deprived of filopodia by cytochalasin treatment. Nature 323:712-715.

Bovolenta P, Mason C (1987) Growth cone morphology varies with position in the developing mouse visual pathway from retina to first targets. J Neurosci 7:1447-1460.

Catalano SM, Robertson RT, Killackey HP (1991) Early ingrowth of thalamocortical afferents to the neocortex of the prenatal rat. Proc Natl Acad Sci USA 8:2999-3003.

Chun JJM, Shatz CJ (1988) Distribution of synaptic vesicle antigens is correlated with the disappearance of a transient synaptic zone in the developing cerebral cortex. Neuron 1:297-310.

Chun JJM, Shatz CJ (1989a) The earliest-generated neurons of the cat cerebral cortex: characterization by MAP2 and neurotransmitter immunohistochemistry during fetal life. J Neurosci 9:1648-1667.

Chun JJM, Shatz CJ (1989b) Interstitial cells of the adult neocortical white matter are the remnant of the early generated subplate neuron population. J Comp Neurol 282:555-569.

Chun JJM, Nakamura MJ, Shatz CJ (1987) Transient cells of the developing mammalian telencephalon are peptide immunoreactive neurons. Nature 325:617-620.

Cragg BG (1975) The development of synapses in the visual system of the cat. J Comp Neurol 160:147-166.

Ferster D, LeVay S (1978) The axonal arborizations of lateral geniculate neurons in the striate cortex of the cat. J Comp Neurol 182: 923-944.

Florence SL, Casagrande VA (1990) Development of geniculocortical axon arbors in a primate. Visual Neurosci 5:291-309.

Friauf E, McConnell SK, Shatz CJ (1990) Functional synaptic circuits in the subplate during fetal and early postnatal development of cat visual cortex. J Neurosci 10:2601-2613.

Garey LJ, Powell TPS (1967) The projection of the lateral geniculate nucleus upon the cortex in the cat. Proc R Soc Lond [Biol] 169:107126.

Ghosh A, Antonini A, McConnell SK, Shatz CJ (1990) Requirement for subplate neurons in the formation of thalamocortical connections. Nature 347:179-181.

Gilbert CD, Wiesel TN (1979) Morphology and intracortical projections of functionally characterised neurones in the cat visual cortex. Nature 280:120-125.

Godement P, Vanselow H, Thanos S, Bonhoeffer F (1987) A study in developing visual systems with a new method of staining neurones and their processes in fixed tissuc. Devclopment 101:697-713.

Goodman CS, Bastiani MJ, Doe CQ, du Lac S, Hefland SL, Kuwada JY, Thomas JB (1984) Cell recognition during neuronal development. Science 225:1271-1279.

Herrmann K, Antonini A, Shatz CJ (1991) Thalamic axons make synaptic contacts with subplate neurons in cortical development. Soc Neurosci Abstr 17:899.

Hickey TL, Hitchcock PF (1984) Genesis of neurons in the dorsal lateral nucleus of the cat. J Comp Neurol 228:186-199.

Ho RK, Goodman CS (1982) Peripheral pathways are pioneered by an array of central and peripheral neurons in grasshopper embryos. Nature 297:404-406.

Hubel DH, Weisel TN (1962) Receptive fields, binocular interaction and functional architecture in the cat's cortex. J Physiol (Lond) 160: 106-154.

Hubel DH, Wiesel TN (1969) Anatomical demonstration of columns in the monkey striate cortex. Nature 22a:747-750.

Hubel DH, Wiesel TN (1972) Laminar and columnar distribution of geniculocortical fibers in the macaque monkey. J Comp Neurol 146: $421-450$.

Humphrey AL, Sur M, Uhlrich DJ, Sherman SM (1985a) Projection patterns of individual $\mathrm{X}$ - and $\mathrm{Y}$-cell axons from the lateral geniculate nucleus to cortical area 17 in the cat. J Comp Neurol 233:159-189.

Humphrey AL, Sur M, Uhlrich DJ, Sherman SM (1985b) Termination patterns of $X$ - and $Y$-cell axons in the visual cortex of the cat: projections to area 18 , to the $17 / 18$ border region, and to both areas 17 and 18. J Comp Neurol 233:190-212.

Innocenti $G$ (1981) Growth and reshaping of axons in the establishment of visual callosal connections. Science 212:824-827.

Kato N, Kawaguchi S, Miyata H (1984) Geniculocortical projection to layer 1 of area 17 in kittens: orthograde and retrograde HRP studies. J Comp Neurol 225:441-447.

Kim GY, Shatz CJ, McConnell SK (1991) Morphology of pioneer and 
follower growth cones in the developing cerebral cortex. J Neurobiol 22:629-642.

Kostovic I, Molliver ME (1974) A new interpretation of the laminar development of cerebral cortex: synaptogenesis in different layers of neopallium in the human fetus. Anat Rec 178:395.

Kostovic I, Rakic P (1980) Cytology and time of origin of interstitial neurons in the white matter in infant and adult human and monkey telencephalon. J Neurocytol 9:219-242.

Kostovic I, Rakic P (1984) Development of prestriate visual projections in the monkey and human fetal cerebrum revealed by transient cholinesterase staining. J Neurosci 4:25-42.

Kostovic I, Rakic P (1990) Developmental history of the transient subplate zone in the visual and somatosensory cortex of the macaque monkey and human brain. J Comp Neurol 297:441-470.

Langdon RB, Frost DO (1991) Transient retinal axon collaterals to visual and somatosensory thalamus in neonatal hamsters. J Comp Neurol 310:200-214.

LeVay S, Stryker MP (1979) The development of ocular dominance columns in the cat. In: Society for Neuroscience symposium, aspects of developmental neurobiology (Ferrendelli JA, ed), pp 83-98. Bethesda, MD: Society for Neuroscience.

LeVay S, Stryker MP, Shatz CJ (1978) Ocular dominance columns and their development in layer IV of the cat's visual cortex: a quantitative study. J Comp Neurol 179:223-224.

Lund RD, Mustari MJ (1977) Development of the geniculocortical pathway in rats. J Comp Neurol 173:289-306.

Luskin MB, Shatz CJ (1985a) Neurogenesis of the cat's primary visual cortex. J Comp Neurol 242:611-631.

Luskin MB, Shatz CJ (1985b) Studies of the earliest-generated cells of the cat's visual cortex: cogeneration of subplate and marginal zones. J Neurosci 5:1062-1075.

Maranto AR (1982) Neuronal mapping: A photooxidation reaction makes Lucifer yellow useful for electron microscopy. Science 217: 953-955.

Mason CA, Christakos S, Catalano SM (1990) Early climbing fiber interactions with Purkinje cells in the postnatal mouse cerebellum. J Comp Neurol 297:77-90.

McConnell SK, Ghosh A, Shatz CJ (1989) Subplate neurons pioneer the first axon pathway from the cerebral cortex. Science 245:978982

Molliver ME, Kostovic I, Van der Loos H (1973) The development of synapses in the cerebral cortex of the human fetus. Brain Res 50: 403-407.

Naegele JR, Jhaveri S, Schneider GE (1988) Sharpening of topographical projections and maturation of geniculocortical axon arbors in the hamster. J Comp Neurol 277:593-607.

Niimi K, Sprague JM (1970) Thalamo-cortical organization of the visual system in the cat. J Comp Neurol 138:219-250.
Quinn B, Weber E (1988) $m$-Phenylenediamine: a novel fluorescent Nissl-like stain for neuroanatomy. Soc Neurosci Abstr 14:219.6.

Rakic P (1977) Prenatal development of the visual system in the rhesus monkey. Philos Trans R Soc Lond [Biol] 278:245-260.

Reinoso BS, O'Leary DDM (1990) Correlation of geniculocortical growth into the cortical plate with the migration of their layer 4 and 6 target cells. Soc Neurosci Abstr 16:213.3.

Rosenquist AC, Edwards SB, Palmer LA (1974) An autoradiographic study of the projections of the dorsal lateral geniculate nucleus and the posterior nucleus in the cat. Brain Res 80:71-93.

Sandell JH, Masland RH (1988) Photoconversion of some fluorescent markers to a diaminobenzidine product. J Histochem Cytochem 36: $555-559$.

Shatz CJ (1983) The prenatal development of the cat's retinogeniculate pathway. J Neurosci 3:482-499.

Shatz CJ, Luskin MB (1986) Relationship between the geniculocortical afferents and their cortical target cells during development of the cat's primary visual cortex. J Neurosci 6:3655-3668.

Shatz CJ, Lindstrom SH, Wiesel TN (1977) The distribution of afferents representing the right and left eyes in the cat's visual cortex. Brain Res 131:103-116.

Shatz CJ, Chun JJM, Luskin MB (1988) The role of the subplate in the development of the mammalian telencephalon. In: Cerebral cortex, Vol 7, Development and maturation of cerebral cortex (Peters A, Jones EG, eds), pp 35-58. New York: Plenum.

Shatz CJ, Ghosh A, McConnell SK, Allendoerfer KL, Friauf E, Antonini A (1990) Pioneer neurons and target selection in cerebral cortical development. Cold Spring Harbor Symp Quant Biol 55:469-480.

Tosney KW, Landmesser LT (1985a) Growth cone morphology and trajectory in the lumbosacral region of the chick embryo. J Neurosci 5:2345-2358.

Tosney KW, Landmesser LT (1985b) Development of the major pathways for neurite outgrowth in the chick hindlimb. Dev Biol 109:193214.

Wahle P, Meyer G (1987) Morphology and quantitative changes of transient NPY-ir neuronal populations during early postnatal development of the cat visual cortex. J Comp Neurol 161:165-192.

Wilson ME, Cragg BG (1967) Projections form the lateral geniculate nucleus in the cat and monkey. J Anat 101:677-692.

Wise SP, Jones EG (1978) Developmental studies of thalamocortical and commissural connections in the rat somatic sensory cortex. J Comp Neurol 175:187-208.

Wise SP, Hendry SHC, Jones EG (1977) Prenatal development of sensorimotor cortical projections in cats. Brain Res 138:538-544.

Yaginuma H, Homma S, Kunzi R, Oppenheim RW (1991) Pathfinding by growth cones of commissural interneurons in the chick embryo spinal cord: a light and electron microscope study. J Comp Neurol 334:78-102. 